
\title{
R Research Soure \\ The Role of SST in Explaining the Economic Growth of Indian Ocean Countries
}

Gil H. Park ( $\square$ hightouchpark@gmail.com )

Daegu University https://orcid.org/0000-0001-9921-9018

Da-Yeong Kim

NRF: National Research Foundation of Korea

Jong-Seong Kug

POSTECH: Pohang University of Science and Technology

\section{Research Article}

Keywords: Climate economics, Indian Ocean countries, climate-vulnerable service expansion, sectoral GDP

Posted Date: April 22nd, 2021

DOI: https://doi.org/10.21203/rs.3.rs-420092/v1

License: @ (i) This work is licensed under a Creative Commons Attribution 4.0 International License. Read Full License 


\title{
The Role of SST in Explaining the Economic Growth of Indian Ocean Countries
}

\author{
Abstract
}

.

Although the concern for the socio-economic effect of climate change has recently increased, its effect on sectoral GDP growth has rarely been researched especially regarding the transcontinental, mid-range area that consists mostly of developing countries like the Indian Ocean countries. Since this area shares an overall similar climate condition represented by the highest temperature as well as economic condition where most of them have experienced lagged economic growth amidst the fastest population growth, such effect will become more critical as their economies consist more heavily of climate-vulnerable sectors. Thus, we analyzed it by two level, e.g., aggregate and sectoral GDP levels. Utilizing both empirical orthogonal and regression functions, we found that the anomalies of GDP significantly decrease when local temperature, which shows high positive correlations with the Indian Ocean Sea Surface Temperature (IOSST) index, increases anomalously. In addition, this trend has been getting stronger recently as local and sea surface temperatures have overall risen. Most importantly, the highest sensitivity to climate change was shown in the service sector, as hypothesized in light of previous studies on the low-skilled and non-tradable service areas with higher adaptation deficit to climate change. We call this tested hypothesis"climate-vulnerable service expansion."

Keywords: Climate economics, Indian Ocean countries, climate-vulnerable service expansion, sectoral GDP 
Introduction

Since economies and humanity have been influenced by climatic factors from the past, it will become more important to study the economic and social impact of climate as its change becomes more conspicuous. This concern was revealed through its impact or causality studies relevant to such various fields as agriculture, energy, labor, mortality, health, and conflict (Zivin and Neidell 2014; Anttila-Hughes and Hsiang 2013; Deschênes and Greenstone 2011; Hsiang et al. 2011; Lobell et al. 2011). Recently, a comprehensive review and analysis of economic and social impact of climate in Carleton and Hsiang (2016) have succinctly introduced and demonstrated such great advances in the literature as verifications of the reduction of maize yields, the increase in conflict, and the decline of global economic growth due to temperature change.

Among such progresses, a growing body of research (Brown et al. 2011; Mendelsohn 2012; Burke, Hsiang, and Miguel 2015; Das 2015; Carleton and Hsiang 2016; Newell et al. 2018; Letta and Tol 2019) addresses how much climate can affect economies and, especially, economic growth. Economic growth and its vulnerability to climate change matter especially when population still increases too fast to sustain per capita gross domestic product (GDP). If this phenomenon persists in many developing countries, including ones in the Indian Ocean region as a large mid-range area between the global and local regions, whose population growth rates are homogenously the highest while indoor manufacturing and modernized or tradable services tend to be less developed and per capita GDPs often lag, it will be important to look at the relation of their GDP and climate (change). In particular, the Indian Ocean countries, where overall similar climatic and economic conditions are found while GDP growth often lags behind population growth in the highest temperature, used not to be researched as much as global or other, more local areas. Since 
this transcontinental area has showed the highest wet-bulb temperature, whose highest levels correspond to the interval unfavorable to economic activity or human vitality and need more energy and cost to make it favorable, the socio-economic impact of its climate (change) is considered more significant or stronger (Im et al. 2017). As the wet-bulb temperature has an upper limit or critical threshold in terms of economic activity or human vitality, any present relation between their GDP growth and climate change would have significant implications to other countries if climate change persists and raises temperature or its related climatic factors. During most of the periods between 1970 and 2014, in the Indian Ocean region (except for the Organization of the Petroleum Exporting Countries (OPEC)), most countries produced much less than approximately 4,000 US dollars as per capita GDP. Accordingly, they tend to still experience the upward phase of the "first wave" of service sector growth (Eichengreen and Gupta 2011). Recent studies have just begun to find the service sector without modernization, which is labor-intensive and particularly sensitive to weather when work is frequently exposed to weather or is made in and after catastrophes, is the most vulnerable sector to climate change (Heal and Park 2015; Fan and Davlasheridze 2019). This servicesector vulnerability has not been highlighted whereas the climatic vulnerability of manufacturing or building construction used to be researched frequently as summarized in IPCC AR5. However, considering many manufacturing activities have been made indoors especially with increasingly lower adaptation deficit in developed economies (Fankhauser and McDermott 2014), where increasingly specialized, skilled, and tradable services support them (Buera and Kaboski 2012b), their climatic vulnerability as well as tradable services' can decrease except the demand-side vulnerability of specific products (e.g., air-conditioners) or servicing (e.g., disaster losses covered by insurance: Wirtz et al. 2013). Further, such demand-side vulnerability may be offset as globally as such demand for more globalized products from other developed countries occurs. 
In developing countries, meanwhile, services are often less modernized and still in the

77 "first-wave" phrase, where service activity tends to be relatively local (e.g., fewer McDonald's), non-tradable, and exposed to weather or heat waves. This exposure implies a higher likelihood of higher adaptation costs in developing countries (Das 2015; Malik and 80 Smith 2012; Mendelsohn 2012), which may naturally lead to the sectoral vulnerability to climate change. In economic development, the service sector used to be the last modernized sector after manufacturing development as the most familiar industrialization process. Hence, the present study examines the role of service sector GDP, which is still mostly traditional, outdoor, or non-tradable in the Indian Ocean countries, in explaining their lagged GDP growth while their population grows the fastest.

To test this hypothesis, hereafter to be referred to as "climate-vulnerable service expansion," it applies the empirical orthogonal function (EOF). The climate-vulnerable services are traditional, non-tradable ones, whose activity tends to be frequently exposed to weather, such as retail and wholesale, foodservice, hospitality, tourism, logistics, and transport (including infrastructure development) whereas modernized ones are software, financial, information and communication, business, knowledge, and legal services. There is no clear-cut dichotomy (of modernization) between the industries under these two waves. However, it is obvious that a local traditional inn with only several rooms in total differs to the Hilton, or an old, weather-sensitive "open-air" restaurant in a small town differs to McDonald's, whose finance or transactions are tradable and supply chains are directly related

96 to information technology and intermediates provided by domestic or transnational manufacturing or branded business services in marketing offices. In light of previous findings of the larger fraction of the traditionality or non-tradability of "first-wave" services in developing countries (Francois et al. 2010; Gervais and Jensen 2019), this study tests whether 
the Indian Ocean region, mostly with developing countries, were more sensitive to climate change.

The EOF has been frequently used for time-series analyses in climate science but was originally developed by a famous statistician, Harold Hotelling, in the 1930s and more widely

104 known as principal component analysis (PCA) in econometrics (Jolliffe 2002). Integrating this technique with regression analysis, whose unknown regression coefficients can alternatively be estimated by or compared with the principal components of regressors where necessary, this study examines the temporal and spatial patterns of the principal components that the most explain the annual mean temperature and precipitation variations and discusses

109 the results for deriving research and policy implications.

\section{Previous Studies}

Why service sector growth is important in understanding the economic impact of

113 climate change in developing countries and why the Indian Ocean countries are selected may

114 need to be clarified in light of previous studies. Concerning economic growth, first, this study

115 considers that the development of these countries' service sector, whose labor productivity has overall remained lower and are still less modernized, traditional or non-tradable, would play an important role in explaining their economic vulnerability to climate change. In the most recent paper examining the GDP-climate relationship with a case of

119 Hurricane Katrina (Fan and Davlasheridze 2019), the service sector turns out the most greatly

120 impacted since it is highly labor-intensive while its demand soars and its supply is limited particularly in and after weather extremes or catastrophes. Although the output (quantity) decrease of the service sector is below the average, its output decrease measured in prices

123 (corresponding to GDP) is the greatest across all industrial sectors. Weather extremes or 124 catastrophes bring negative effects intensively as emphasized in IPCC AR5, but the 
125 vulnerability of services (as the labor-intensive sector) to climate change is obvious as in 126 Heal and Park (2015) and Fan and Davlasheridze (2019). growth of the still traditional service sector (Bryceson 1996; Eichengreen and Gupta 2011) or

129 lower labor productivity with demographic and health effects potentially negative to economic growth. Even those studies, however, have not demonstrated the relationship between climate change and service sector growth (in GDP). As in many other developing countries, the population in the Indian Ocean region tends to have increased faster due to the higher birth rate, which may raise the contemporaneous cost of supporting economically

134 inactive population (Hock and Weil 2012) as an "demographic onus" (Ogawa et al. 2005) to

135 in turn increase the opportunity cost of private and governmental investment at the social level. At the same time, the highest wet-bulb temperature potentially threatens (public) health and (economic) labor force conditions as well (Im et al. 2017).

In general, economic growth in developed countries was made with urbanization and industrialization centered on manufacturing, begetting internal and external or agglomeration economies of scale. Experiencing post-industrialization, their expanding service sector has also become modernized and tradable. The production of the modernized sector (e.g., software, financial, information and communication, business, knowledge, and legal services)

143 has become predominant in the share within the service sector, and it has also contributed

144 increasingly to their GDP growth especially in developed countries (Sheehan 2006; Szirmai and Verspagen 2015).

Although the GDP share of manufacturing, which is mostly indoor, has also become

147 relatively lagged and contributed less and less to GDP growth in developing countries as

148 Szirmai and Verspagen (2015) demonstrated, expanding service sector's contribution to GDP

149 growth is not as much as developed ones.' In typical economic development stages, the 
service sector is the last modernized area after manufacturing development, which often represents the most familiar industrialization process. In many developing countries, their service sector still tends to have remained traditional and, thus, mostly outdoor or nontradable even until recently, while their service GDP and the GDP share of services have often increased despite their still lower productivity and higher sensitivity to climate change. In developed and middle-income countries, meanwhile, it had increased and then typically decreased across countries over time once before it began to show the "second wave" (Eichengreen and Gupta 2011) of the GDP share of services in economic growth (e.g., before the year of 1990 or around the real per capita GDP of 4,000 US dollars). This implies the rationale of researching developing countries with a focus on their GDP growth lags

160 despite their service sector growth, which in fact used to be made without sufficient modernization of that sector and with higher sensitivity to climate change. researched among developing countries. Recently, the relationship between economic growth

164 and climate has been examined from both global and local perspectives. While mid-range 165 regions have been less examined yet, many studies have tended to find the global connections between economic growth and climatic factors. Burke et al. (2015) found that overall economic productivity and temperature have a non-linear relationship globally, and annual optimum productivity temperature is $13^{\circ} \mathrm{C}$. In the case of agriculture, often classified as the

169 primary industry, climate phenomena such as El Niño Southern Oscillation (ENSO), Indian

170 Ocean Dipole (IOD), and North Atlantic Oscillation (NAO) cause significant changes in cropland and crops (almost) globally (Heino et al. 2018). El Niño and La Niña also contribute to a change in global yields of major crops (Iizumi et al. 2014). This stream of research has a strength in analyzing a global trend but, at the same time, often has a weakness in generalizing its results since there are often larger variations in relevant factors (Kim et al. 
2017). Still, it is difficult to discern how common climatic factors are in affecting economic growth from the global perspective, because economic growth conditions and exposure vulnerabilities to climatic change differ by region.

Another important stream of research, made from a local perspective, used to focus on specific countries or an individual country. From these country- or local-level studies, there has also been found an overall negative relationship between macroeconomic productivity and annual mean temperature rise in developing countries (Letta and Tol 2018; Fankhauser and McDermott 2014; Dell et al. 2012). For instance, there has been a lot of research on the GDP-climate relations of separate countries or areas, which may or may not be contiguous or proximate to one another. This research stream, whose results used to be demonstrated by analyses of such GDP-climate relations in individual countries or local areas as the sensitivity of sectoral output to weather variability in the U.S. (Lazo et al. 2011), the economic impacts of surface temperatures and cyclones around the Caribbean (Hsiang 2010), and the relationship between precipitation and the GDP growth rate in the Republic of South Africa (Jury, 2002), has an advantage in generalizing its results to the areas with similar conditions. Meanwhile, due to its limited geographical scope, its implications are often limited. Whether it is focused on global or local areas, the interest in future climate changes and their impacts on economies is steadily increasing. Considering this increasing interest, it will also become more important to examine such a "mid-range" or transcontinental region (of countries) with similar climatic conditions as the Indian Ocean countries, where GDP and climate changes could potentially be interlocked while their per capita GDP "homogenously" tends to lag behind their increasing population. Further, if their "more climate-sensitive" economic production may determine their human vitality and quality of life more critically, the relationship between Indian Ocean climate change and economic growth will have more significant regional, social, and economic implications. 
If a warming trend in the future follows the current one, global income was forecasted to decrease about $23 \%$ by 2100 (Burke et al. 2015). Depending on mitigation target levels of $1.5^{\circ} \mathrm{C}$ and $2^{\circ} \mathrm{C}$, there will be a big difference in economic damages at the end of this century, so Burke et al. (2018) emphasized achieving the $1.5^{\circ} \mathrm{C}$ target. Pretis et al. (2018) also found there is a larger negative impact on economic growth at $2{ }^{\circ} \mathrm{C}$ warming, but it still requires attention considering the uncertainty of the results.

Although these studies have simulated climate-economy models under future climate scenario as they perceive climate change to be global, they may have more significance in Indian Ocean countries. Recent studies (Davis and Vincent 2017; Waha et al. 2017; Yusuf and Francisco 2009) have showed Indian Ocean areas are particularly vulnerable to climate change or variability. In light of these findings, this study also began with questioning whether and how strongly such future climate change would affect economic growth. It has already been known that the Indian Ocean affects African, Middle East, and South Asian climate (Bader and Latif, 2003; Saji et al. 1999; Webster, Moore, Loschnigg, and Leben 214 1999; Yang et al. 2007).

Hence, transcontinental, Indian Ocean countries are likely to be vulnerable to climate change in the Indian Ocean, especially because many of these populous areas often have

217 limited (skilled) labor productivity, let alone insufficient capital (to supply manufactured 218 goods largely), while their climate is often unfavorable to all-day outdoor work or service (Im 219 et al. 2017). Despite such theoretical and seemingly obvious vulnerabilities, however, Indian 220 Ocean countries have been less researched empirically. Drawing on that outdoor work or the service exposed to weather and climate is especially common in many of the agricultural and non-tradable service activities rather than manufacturing in developing countries (Zivin and Neidell 2014; Heal and Park 2015), this study presents a hypothesis that the higher service 
sector GDP is, the more vulnerable or sensitive economies are to climate change in Indian

Ocean countries.

The hypothesis is based on that the supply and demand of the "first-wave" service is the most sensitive to climate (change). In this study, the increase in service sector GDP over the Indian Ocean region is understood as "climate-vulnerable service expansion." It would be comparable with "climate-invulnerable service expansion" in developed countries.

Up to now, it is hard to deny that there is little research on the relationship between the climatic factors and the economic growth of countries surrounding the Indian Ocean. Most of the Indian Ocean countries are developing countries, whose economic activities tend to be relatively more outdoor or less air-conditioned than indoor or office (desk) work and thus susceptible to climate exposure (Im et al. 2017). In Indian Ocean countries, the service share increase has been concentrated on first-wave, climate-vulnerable services (Bryceson 1996; Eichengreen and Gupta 2011). Their vulnerability to climate change is considered due to the lagged share of manufacturing and the services invulnerable to climate change while they often have weather extremes and even deadly heat waves (Im et al. 2017).

It suggests their economies can be relatively easily affected by climatic factors. Our focus is that the economic growth of these countries has the common denominator, Indian Ocean. In analyzing the relationship between changes in service sector GDP and climate in this wide but overall similarly-conditioned region, we will concentrate on an interlocking of GDP with sea surface temperature (SST), local and "gridded" global surface air temperature, and precipitation.

\section{Data and Models}

\section{Economic data}


249 (Feenstra et al. 2015), which is composed of various economic variables about 182 countries and has been widely used in the economics literature together with the World Bank (WB) national accounts data (https://data.worldbank.org). (PWT and WB data are also to consistently show correlation coefficients over 0.90 for the same variables in most countries.) We used the real GDP at chained PPPs in million 2011 US dollars for considering living standards by country and comparing GDPs based on the same criteria. A 10-year high-pass filter was applied to GDP, in order to exclude long period factors or increasing trends such as capital and population (or labor) increases, and consider effects of climate factors on interannual time scale. The period of the raw data is annual, less than 10 years, which is a period that is considered often as a mid-term (e.g., the Juglar cycle) both in econometrics and climate science, so it can basically be seen from an inter-annual perspective. Before using the high-pass filter, we applied the natural log of the data to increasing normality, and then the annual mean was subtracted by country, as usual in making the "covariance matrix" in EOF. Through this pre-processing, the anomalies of such climatic variables as SST, local temperature, precipitation and such economic variables as GDP, capital, and labor (or population) can be computed so that the covariance (and, accordingly, correlation) between the time-series of each locality (or "map" in terms of climate science) is derivable. The GDP share of the service sector was calculated using services (sectoral value added in constant US dollar) and GDP, utilizing the WB data. These two data were about the 256 countries, so we matched them only if both have the same country.

\section{Climatic data}

As climatic data, temperature, precipitation, and SST are used in this study. The scale

272 of the temperature and precipitation data is two-fold. The first one was the country-level 
average climate data constructed by Climate Research Unit (CRU) at the University of East Anglia (CRU CY, version 3.24.01, Harris et al. 2014). It is referred to as local temperature and precipitation, respectively.

The second one was the global climatic index from CRU TS ver. 4.01, gridded at 0.5 degrees. Temperature is the annual average temperature in Celsius, and precipitation is the total amount of yearly precipitation measured in millimeters. The SST data was extended reconstructed sea surface temperature version 3, gridded at 2 degrees (ERSST ver. 3b), by Smith et al. (2008). The 10-year high-pass filter was applied to these data in the same process as the economic data. The 8- and 16-year high-pass filters were also experimentally applied,

282 but main conclusion does not change.

\section{Estimating models}

The precision of estimation of the relation between climate and economies would be improved if analyses are focused on an area sharing common economic, natural, and climatic characteristics in the long term. For this improvement for a still relatively large, transcontinental area, as described earlier, high-pass filtering was used in this study. It was adopted for removing the long-term trend as precisely as possible before calculating anomalies as a common, interdisciplinary econometric and climate research technique applicable to the Indian Ocean region sharing such homogeneous characteristics. Then, the EOF and multiple linear regression were applied to analyzing GDP. For the sake of concise discussion, the more detailed explanation of how EOFs and regression were integrated is provided (together with Fig. 3) in the next section. The EOF is widely adopted as a function to focus on the time-series component among the PCA methods and has been

296 the most commonly used in climate analysis. However, this method used not to be applied in 297 the econometric time-series analyses as frequently as climate time-series analyses, though 
298 PCA itself was originally developed by an statistician and economist Harold Hotelling, so 299 that an interesting result may be expectable.

300 We selected a specific area of latitude $30^{\circ} \mathrm{W}-125^{\circ} \mathrm{E}$, longitude $45^{\circ} \mathrm{S}-45^{\circ} \mathrm{N}$ around

301 the Indian Ocean. As mentioned earlier, these countries respond sensitively to heat waves and

302 climate change (Im et al. 2017). The analysis period is 45 years and spans from 1970 to 2014

303 (as the last year in PWT 9.0) for matching PWT and WB with the years not available for

304 most of the observations excluded, while the earliest year when the raw data are possible to

305 be constructed from both PWT and WB regardless of missing values was 1960.

306

\section{Results and Discussion}

308 Fig. 1a shows the first EOF mode, which explains $21.7 \%$ of the anomalies of GDP for 309 the period of 1970-2014. From now on, we will call the anomalies of GDP just GDP for convenience unless necessary. Most countries have negative signs except a few countries near the Sahara Desert of North Africa. A time series of the first EOF mode is shown in Fig.

$3121 b$, showing interannual variation.

313 In order to examine the relationship between GDP and climate factors, correlation between the first EOF mode and global SST is calculated. The first EOF mode of GDPs is related to climate factors as closely as it was assumed; particularly to Indian Ocean SST and "gridded" global surface air temperature, which shows a maximum correlation value of 0.60

317 (see Fig. 2a). Correlation values with SST are significantly high overall in the Indian Ocean.

318 In addition, the first EOF mode is significantly correlated to land temperature as shown in

319 Fig. 2b. In particular, the relation is higher in and round coastal areas. It suggests that the countries have anomalous negative GDPs when SST and temperature are higher than their average by country over 1970 to 2014 . This is consistent with the results of previous research. According to the Burke et al. (2015), global economic growth has a convex curve 
that shows its maximum at 13 degrees Celsius. Dell et al. (2012) have also showed a decrease in GDP by $1.3 \%$ for developing countries with a simple linear regression in the case of increasing one degree Celsius. In particular, the countries near the equator tend to have the highest annual temperature and shows the greatest sensitivity, e.g., a negative change in response to a temperature increase in this research. Meanwhile, the pattern of SST in the

328 Pacific Ocean is similar to the decaying phase of El Niño event. A correlation analysis with Niño3.4 index in winter (DJF, https://climatedataguide.ucar.edu/climate-data/nino-sstindices-nino-12-3-34-4-oni-and-tni) and PC1 time series shows relatively weak correlation. The correlation value is 0.37 significantly at the $95 \%$ confidence level (not shown). While Fig. 2 shows the relationship between PC1 time series and climate factors, Fig. 3a illustrates the correlation as a "direct" relationship between GDP and local temperature for each country. Many countries exhibit negative correlation, indicating that GDP tends to decrease when local temperature is anomalously high. Some countries such as United Arab Emirates (-0.47), Cabo Verde (-0.42), Botswana (-0.40), and Mozambique (-0.39) show highly negative correlations. Although they are seemingly oil or mineral exporting countries, which have been recently researched regarding the direct effect of climate change on mines (Odell et al., 2018), or have recently increased investments in (weather-sensitive) tourism or infrastructure expansion, more research seems to call for, even disregarding service sector growth.

Fig. 3b demonstrates how well GDP is expressed by two climate factors, local temperature $\left(t m p_{i t}\right)$, and precipitation $\left(\right.$ pre $\left._{i t}\right)$ in equation (1). We used a multiple linear regression for the period of 1970 to 2014 under the following formulation, whose climatic coefficients are solved by country:

$$
\ln \left(G D P_{i t}\right)=\alpha t m p_{i t}+\beta \text { pre }_{i t}+\varepsilon_{i t}
$$


After solving climatic coefficients by each country, we reconstructed GDP putting them into the equation. If the error is small, the correlations between GDP and reconstructed GDP will be high. In general, about $90 \%$ or higher of GDP variations can be explained with labor and capital stock only. Since the high-pass filter was applied to all the variables in our analysis, however, climate factors are supposed to explain much of the GDP residuals after being explained by population and capital over a long period. Thirty-one countries show Pearson correlation coefficients $(r)$ significant at the $90 \%$ confidence level, and the highest $r$ value is 0.58 in Botswana.

Before proceeding to analyzing the climate-sectoral GDP relations, in the case of GDP, it can be known that the economic effects of temperature and precipitation are closely related to SST. This implies that the meteorological processes and maritime processes can be coupled together in affecting local climate and GDP changes. For figuring out this, we made the Indian Ocean SST index (IOSST) by averaging SST over the area of latitude $50^{\circ} \mathrm{E}-$ $100^{\circ} \mathrm{E}$, longitude $20^{\circ} \mathrm{S}-30^{\circ} \mathrm{N}$.

Since the contemporaneous correlation values between IOSST and the global temperature are very high, IOSST is highly likely to increase if the global temperature increase (see Fig. 4a). Fig. 4b also show that the IOSST is also correlated to the precipitation in countries surrounding Indian Ocean. Negative relations seem prevalent in Southern Africa,

367 Southeast Asia, and Oceania when SST is higher than usual, whereas positive ones are

368 discernable in the areas upper in the horse latitudes including ones around the Black Sea and the Caspian Sea. The positive shaded countries of the first EOF also tend to be gathered in and around the Sahara Desert where there are significant, positive correlation values between

371 IOSST and precipitation (Fig. 1a). Although those countries are few, their GDP seems to be 372 affected by precipitation. In Fig. 4c, the direct relationship between IOSST and GDP also 
shows the negative correlations in many countries like the relationship between global temperature and GDP.

Next, to test whether the association between GDP and climatic factors has been getting stronger, we conducted an experiment comparing reconstructed GDPs between the past and recent decades. Within 45 years of analysis period, the period of the past decades is from 1975 to 1994 , e.g., over the first 20-year period, whereas the period of the recent decades is for the next 20 years. Two points are particularly discernable in the scatter diagram (Fig. 5).

First, the number of the countries, whose correlations of GDP and reconstructed GDP (using local temperature and precipitation) are significant at the $90 \%$ level, has been increasing recently. Given the very high correlation between IOSST and local temperature, the geographical scope of Indian Ocean climate's influence seems to be growing during the recent two decades, e.g., over 1995 - 2014. Second, their correlation values have overall become larger than the past decades. These points are also supported by 26 figures of 20 -year moving window correlation starting from 1970-1989 until 1995-2014. The average correlation value increased (e.g., slope $=0.0004)$ for the countries that were significant in Fig. $5 \mathrm{~b}$ and the number of significant countries increased (e.g., slope $=0.1508)$. In terms of GDP, rather than each sectoral GDP, they also reflect the overall (potential) vulnerability of the Indian Ocean countries to climate change under a (possible) warming trend at the global 391 level.

Analysis proceeds to sectoral GDP, then. In accordance with the convention, GDP could be divided into agriculture, industry, and service sectors. Lastly, we conducted EOF analyses by each GDP sector for examining which GDP sector is most affected by climate factors (Fig. 6). Although our focus is on how strongly climate change affects the growth of

396 first-wave services in developing countries in the Indian Ocean region, GDP itself (rather 397 than sectoral GDP) and the other sectors, e.g., agriculture and manufacturing in this region, 
may need to be comparatively discussed before examining the service sector itself. Regarding

399 African agriculture, the production of main crops was forecasted to be reduced because of a warming trend by mid-century in model simulation (Schlenker and Lobell 2010). In their experiment to examine an inter-annual comparison, not a short-term oscillation, African major crops turned out vulnerable to climate change. This happened in not only African main crops but also U.S. main crops. Crop yields sharply decreased when the temperature exceeded specific temperatures (Schlenker and Roberts 2009). The productivity of labor also fell as the daily maximum temperature exceeded a threshold especially in climate-exposed industries such as construction (Zivin and Neidell 2014).

Regardless of economic or climate science, regression or correlation analysis used to be frequently made regarding the relationship between the ratio of sectoral GDP to the total GDP and other variables. Until the early 20th century, relevant studies demonstrated the relations between GDP and the GDP share of services was not statistically significant (Clark, 1940; Fisher, 1939). Until the mid-twentieth century, their correlations between the GDP

412 share of services and the log per capita income (Chenery 1960), and between the GDP share of services and the per capita income (Kutznets 1957) have also turned out statistically not significant in regression or correlation analyses. using per capita GDP data since the industrial revolution, with their square values as dependent variables and the GDP share of services as an independent variable. Their resulted graph showed a concave shape to the origin that indicates a non-linear relationship. More recently, Buera and Kaboski (2012a, b) have found the relationship between the share of services and log per capita GDP to be linear. anomalies of service sector GDP (in comparison with other industrial sectors) and climatic 
variables in a common analytic framework to derive the covariance matrices, correlations,

424

425

426

427

428

430

431

432

433

434

435

436

437

438 and regression coefficients. The correlation between changes in climate and the GDP share of services was not statistically significant, since the long increasing trend is apparent overall for most developing countries over much longer than 10 years when climate change occurred in less magnitude but also steadily as well.

Agriculture in the Indian Ocean countries have often been regarded as the most important or higher in its GDP share than the global average. However, it takes the smallest proportions of the three industrial sectors. The most contributive sector to GDP is manufacturing or service sector, depending on the countries and year.

In our analysis, the number of countries is 39 (in Indian Ocean region within latitude $50^{\circ} \mathrm{E}-100^{\circ} \mathrm{E}$, longitude $20^{\circ} \mathrm{S}-30^{\circ} \mathrm{N}$ ). The analysis period is from 1970 to 2014 . Thus, the number of observations equals 1,755 .

The PC1 time series of the service sector is similar to total GDP time series, and the correlation value is 0.85 . It is significant at the $99 \%$ level. Interestingly, however, the other two sectors' EOF 1 mode did not seem as sensitive to climate. While we assumed that the agriculture tends to be also sensitive to climate, together with services, in most Indian Ocean countries as developing countries, our results describe their service sector is the much more sensitive to climate change than agriculture and manufacturing.

In fact, based on the GDP composition by sector, the value of eigenvector is consistent with that of the country with the largest share in the service sector. Bryceson (1996) explained rural service sector development in sub-Saharan Africa as "deagrarianization," which means a macroeconomic transition from agrarian development. As discussed when we reviewed the literature, Eichengreen and Gupta (2011) also showed an increase in the GDP share of "first-wave" services in developing countries, which implies the increasing sensitivity of GDP to climate change, although their phases differ by country. 
Although the GDP share of services has been increasing in both developing and

449 developed countries, in addition, scientific, economic, and policy measures to adapt to the

450 climate changes tend to be developed more extensively and intensively in developed

451 countries (Burke et al. 2016). Developing countries often suffer from the "adaptation deficit"

452 because of insufficient public services or institutions and private demand, let alone

453 inefficiency in the market exchange of relevant goods and services (Fankhauser and

454 McDermott 2014).

Services correspond to International Standard Industrial Classification (ISIC) divisions

50-99. These divisions include wholesale and retail trade, transport, and government,

financial, professional, and personal services (wdi.worldbank.org/table/4.2). While such

"second-wave" services as financial, communication, software, and knowledge, legal and

business services, in general, the services centering on retail and wholesale, foodservice, hospitality, tourism, logistics, and transport in the Indian Ocean countries are typically low skilled and non-tradable. Thus, in light of the "climate-vulnerable service expansion"

462 hypothesis, the service sector was assumed to be still sensitive or vulnerable to climate

463 change in many Indian Ocean countries after 1990s, and it is verified in analysis as in Fig. 6 and Fig. 7. (Agriculture also shows a locally similar result when analyzing agriculture's EOF, but this relationship is conspicuous because of the local effect of temperature and precipitation around a steppe climate region, not the overall Indian Ocean countries.)

\section{Conclusions}

469 Climate has affected a wide variety of fields in humanity and economies. Its change was considered to engender a significant effect to economic change, which is representable

471 by economic growth. This study formulated its main hypothesis of "climate-vulnerable

472 service expansion," considering the still larger fraction of the traditionality or non-tradability 
473 of "first-wave" services in developing countries (Francois et al. 2010; Eichengreen and Gupta

474 2011; Gervais and Jensen 2019). Then it tested whether the Indian Ocean region, mostly with

475 developing countries, were more sensitive to climate change.

476 We found the overall negative relationship between GDP and temperature in most of

477 the Indian Ocean countries, in the analysis for the first EOF mode. The mid-term, 10-year

478 high-pass filter was applied, and it produced better results in accordance with other logical

479 findings to together support the main hypothesis when EOF, multiple linear regression,

480 correlation, and bootstrapping were consecutively conducted or integrated.

481 The PC 1 time series turned out strongly similar to the Indian Ocean SST time series

482 when Indian Ocean countries have negative signs in the first EOF mode. This implies that the

483 GDP of countries with such negative signs will become anomalously low if SST is

484 anomalously high. This is also supported by the direct relationship with GDP and climate

485 factors indicates negative correlations. Some countries, of course, have positive correlations,

486 but these values are very small and not significant.

487 These findings come from the analysis employing IOSST because temperature and

488 precipitation are affected by IOSST. There are overall highly positive contemporaneous

489 correlations between IOSST and "gridded" global surface air temperature in Indian Ocean

490 regions. Since there have rarely been any studies of a mid-range, transcontinental area's

491 relationships between SST and GDP changes especially regarding service sector growth, they

492 are noticeable results in explaining GDP through understanding Oceanic influences. If we can

493 calibrate this estimation more precisely and forecast the future SST in climate models, the

494 economic growth of countries near the (Indian) Oceans would be better predicted. Recently,

495 Frölicher and Laufkötter (2018) revealed marine heatwaves (MHWs) have been longer-

496 lasting and more frequent and there is no guarantee that this phenomenon is not accelerated 
as the global mean temperature rises. The transcontinental Oceanic influence, hence, may become more significant for understanding SST and this effect on GDP.

500 impact of potentially rising global temperatures in the future might become serious.

501 Considering this, we compared the correlations between reconstructed GDP and real GDP

502 during the past decades (1975-1994) to the recent decades' (1995-2014), as well. As a result, the correlation values were as high as expected, and the number of significant countries increased than the past decades. Our results imply the Indian Ocean countries may be more sensitive (or vulnerable) to climate factors, but this sensitivity has been growing recently. It would become increasingly recommendable, therefore, that these countries should find a way out of the damage by potential climate change (e.g., disaster relief efforts, irrigation system, and developing heat tolerance) and develop the ability to adapt and mediate through policies and research, which can be helped by developed countries. examined which is affected by climate factors among GDP sectors, e.g., agriculture, manufacturing, and services. The "first-wave" service sector, which is regarded as much more climate-vulnerable than in developed countries, turned out the most sensitive to climate change. It has also showed the noticeably highest correlation $(r=0.85)$ with the PC 1 time series of GDP, among three industrial sectors. The larger fraction of the service sector seems to lead to such overall higher sensitivity in Indian Ocean countries, which might also occur in other developing countries outside the Indian Ocean region. The influence of other Oceans on economic growth may need to be researched, considering such results, further in the future. overcome. Global climate data have shorter data than year (e.g., monthly), whereas economic data is yearly or quarterly while it is extremely hard to obtain long-term quarterly data for 
every country. Only for limited cases, usually for developed countries, such long-term

523 quarterly economic data is obtainable at present. If the seasonal or daily scale climate has an

524 impact on economies, the annual mean treatment may not produce an offset effect. There is

525 also a limit to seeing global GDP effects on a more local scale, as it would be often possible

526 only by assuming based on the available data from specific or nearby countries where data

527 exist. Another question is that economic and social impacts on climate could be nonlinear

528 (Carleton and Hsiang 2016). It is important to see linear relationships, such as correlation, but

529 it is also important to find relationshipts where rapid changes occur after a certain threshold.

530 For example, a wet-bulb temperature of 35 degree Celsius can be considered an upper limit

531 on human survivability ( $\mathrm{lm}$ et al. 2017; Sherwood et al. 2010). From a vegetative point of

532 view, the photosynthetic rate of plants sharply degreases around 40 degrees. It is necessary to

533 see how the economy is affected when it is above or below a certain temperature, i.e. its

534 relationship with extreme tempeartures. Therefore, various and technical experiments are

535 needed to grasp the GDP-climate relationship in the Indian Ocean countries, which may call

536 for an improved or alternative approach to clarifying and controlling those complex factors

537 and influences.

538

539

540 

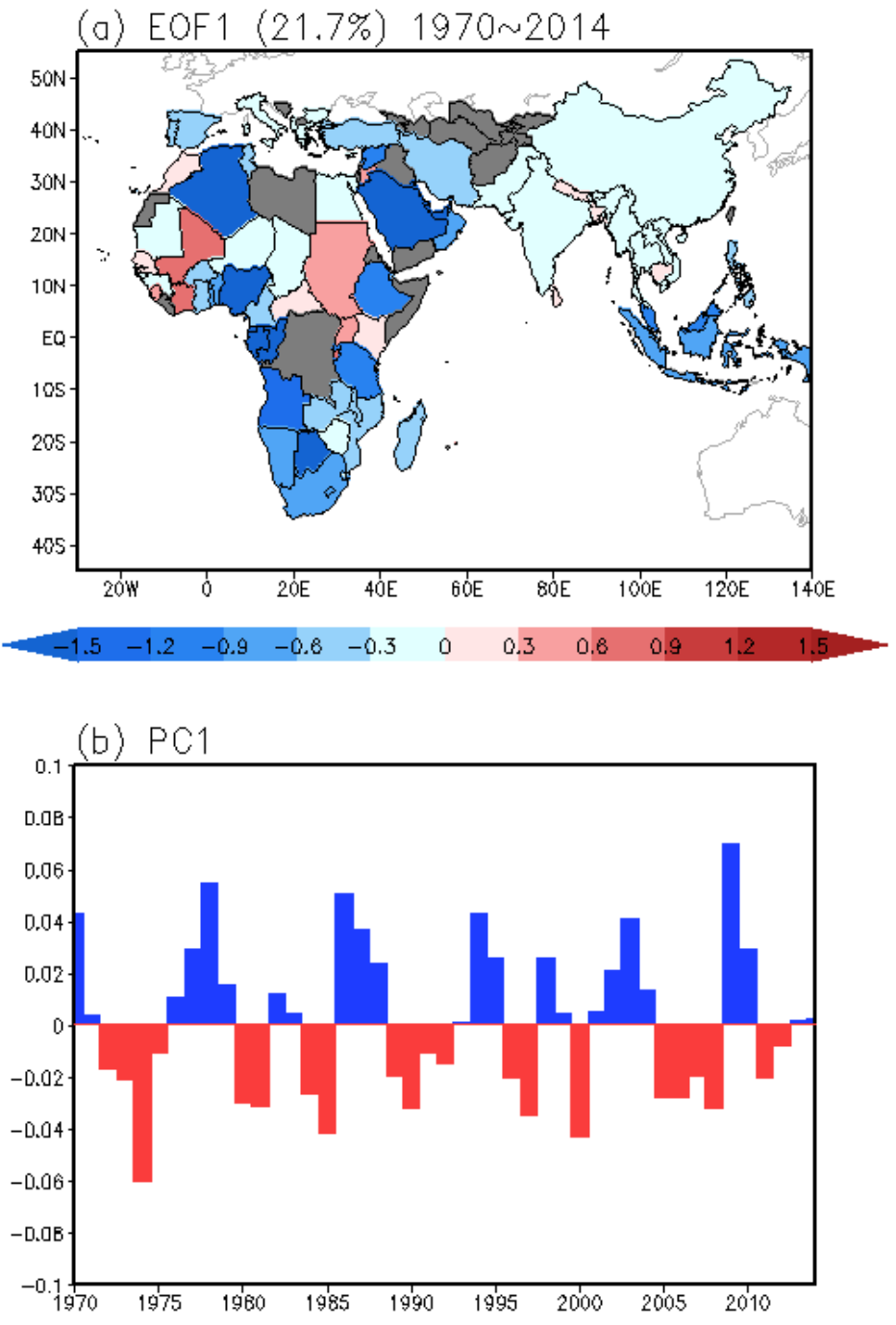

542

543 Fig. 1 EOF1 (a) of GDP in the target area $\left(30^{\circ} \mathrm{W}-125^{\circ} \mathrm{E}, 45^{\circ} \mathrm{S}-45^{\circ} \mathrm{N}\right)$ during the period 544 1970-2014. The percentage variance is $21.7 \%$ explained by the EOF1 spatial pattern. No data 545 is denoted by gray shaded regions. The first principle component time series (b) is 10-year 546 high pass filtered in the same period. 


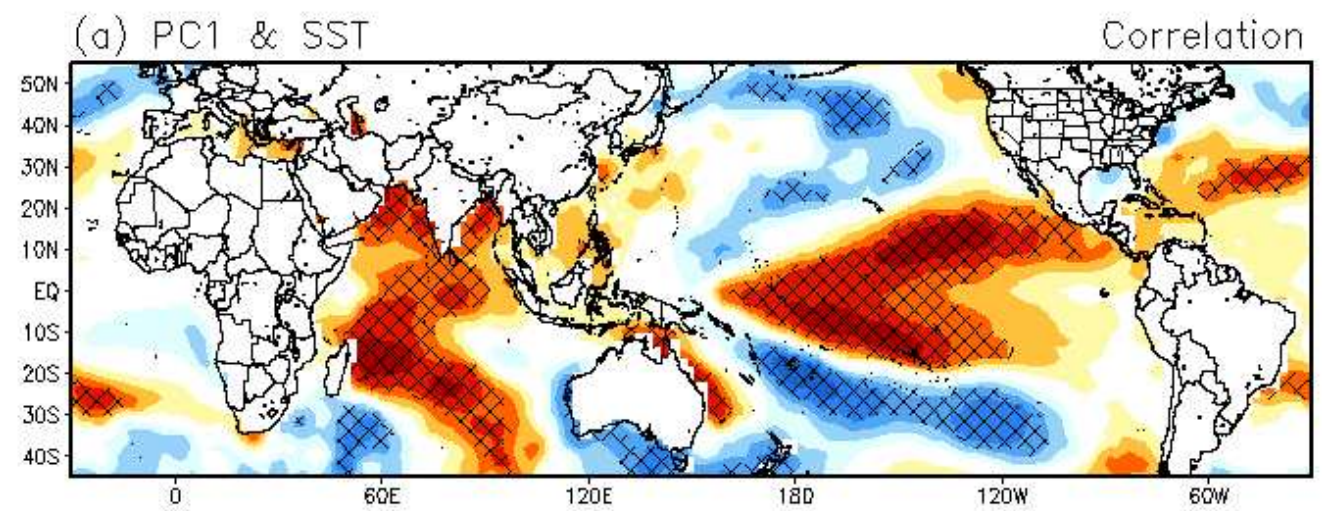

(b) PC1 \& Temperature

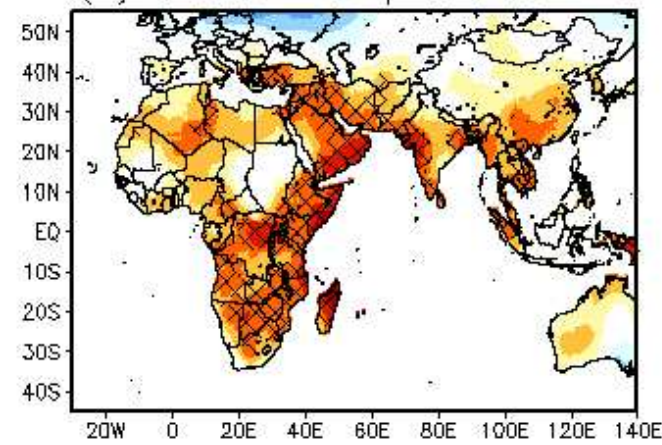

(c) PC1 \& Precipitation

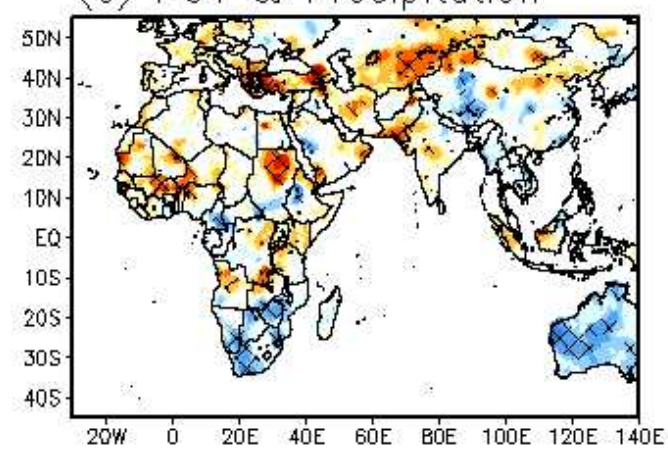

549

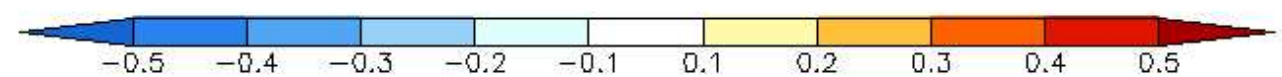

550 Fig. 2 Correlation coefficients of SST (a), global temperature (b), and global precipitation (c) with respect to PC1 time series during the period 1970-2014. The values over $90 \%$ confidence level based on the student $t$-test are denoted by hatch marks. 

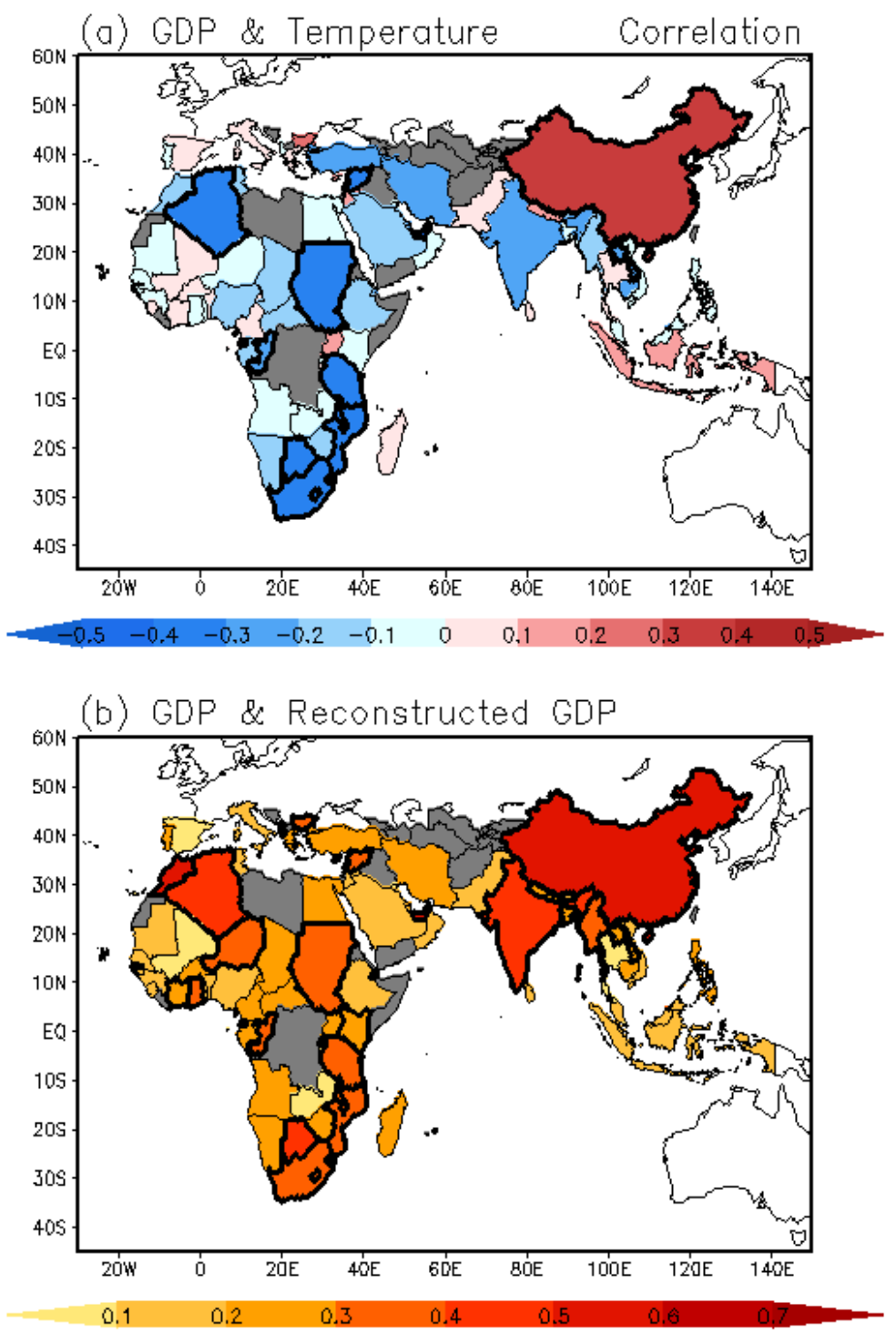

555 Fig. 3 Correlation coefficients of local temperature with respect to GDP during the period 556 1970-2014 (a). Correlation coefficients of GDP with respect to reconstructed GDP $557\left(\ln \left(G D P_{i t}\right)=\alpha t m p_{i t}+\beta\right.$ pre $\left._{i t}+\varepsilon_{i t}\right)$ during the period 1970-2014 (b). The values over $55890 \%$ confidence level based on the student $t$-test are denoted by the thick black line. No data 559 is denoted by gray shaded region 

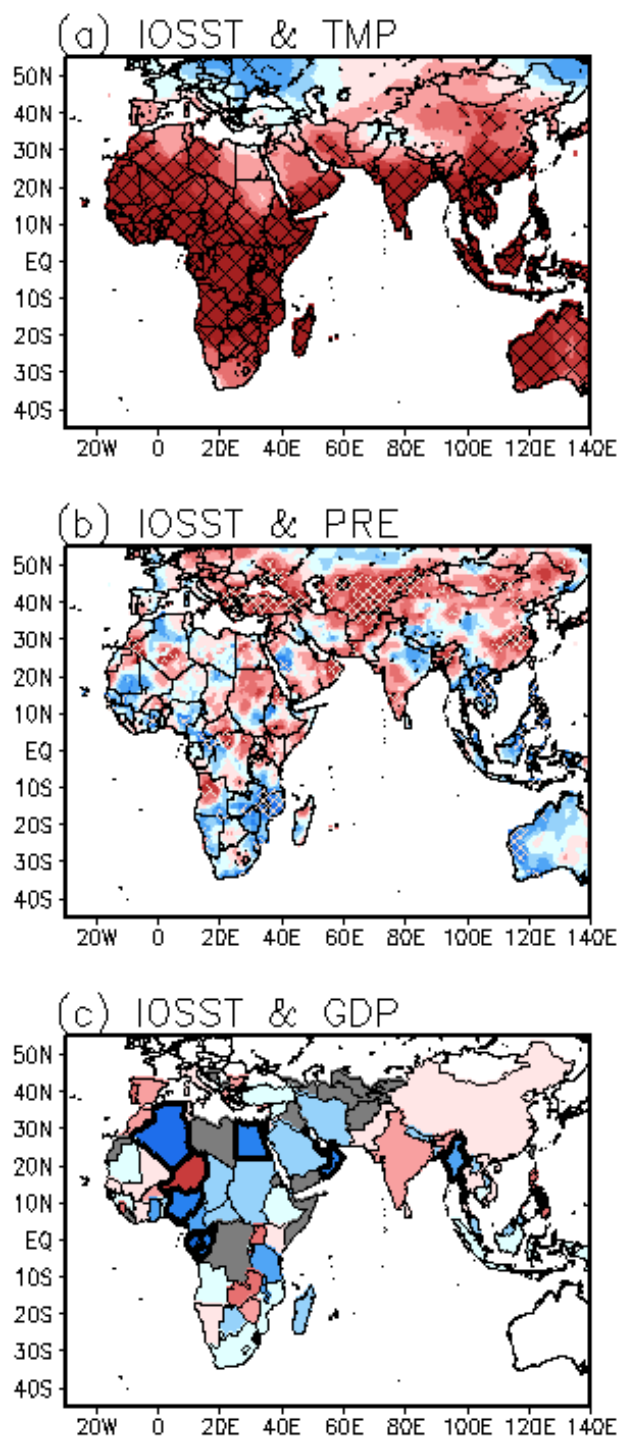

561

562 Fig. 4 Correlation coefficients of global temperature (a), global precipitation (b), and GDP (c) 563 corresponding to the reconstructed index based on the Indian Ocean SST $\left(50^{\circ}-100^{\circ} \mathrm{E}, 20^{\circ} \mathrm{S}-\right.$

$56430^{\circ} \mathrm{N}$ ). The values over $90 \%$ confidence level based on the student $t$-test are denoted by hatch 565 marks $(\mathrm{a}, \mathrm{b})$ or thick black line $(\mathrm{c})$ 

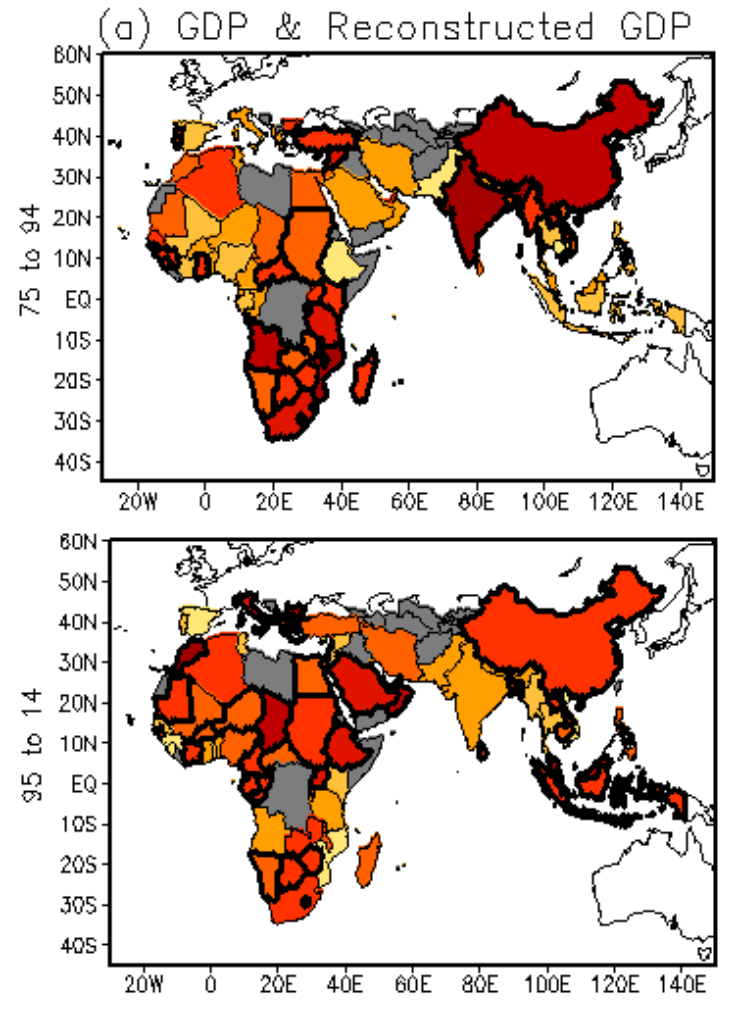

$\begin{array}{llll}0.1 & 0.2 & 0.3 & 0.4\end{array}$

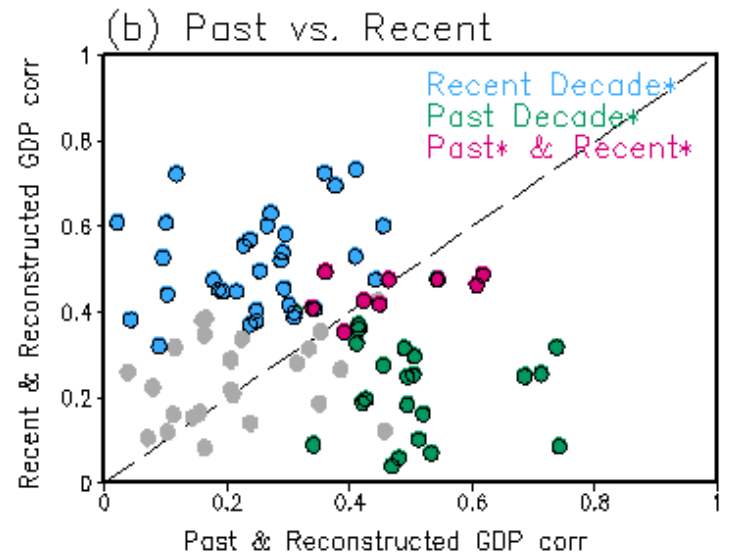

567

568

569

570

571

572

573

574

Fig. 5 Correlation coefficients of GDP with respect to reconstructed GDP from 1975 to 1994 (the past decades) in the upper (a). Correlation coefficients of GDP with respect to reconstructed GDP from 1995 to 2014 (the recent decades) in the lower (a). Scatter diagrams for the correlations between GDP and reconstructed GDP for the past decades and the recent decades by country. The values over $90 \%$ confidence level of the past decades, recent decades, and both denoted by green, blue, and pink respectively. 
(a) Service EOF1 (23.5\%)

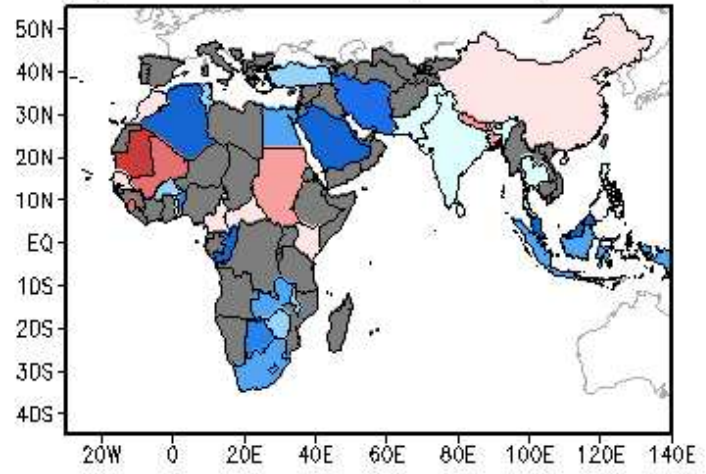

$\begin{array}{llllll}-1.5-1.2-0.9-0.6-0.3 & 0 & 0.3 & 0.6 & 0.9\end{array}$

(b) Service PC1 (Corr 0.85***)

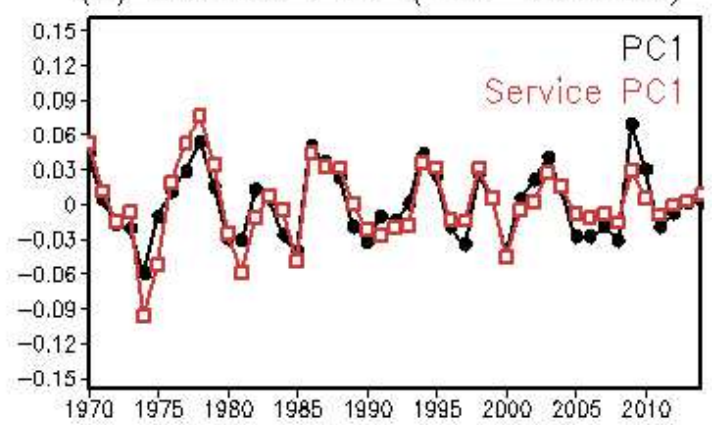

(c) PC1 \& SST, Temperature
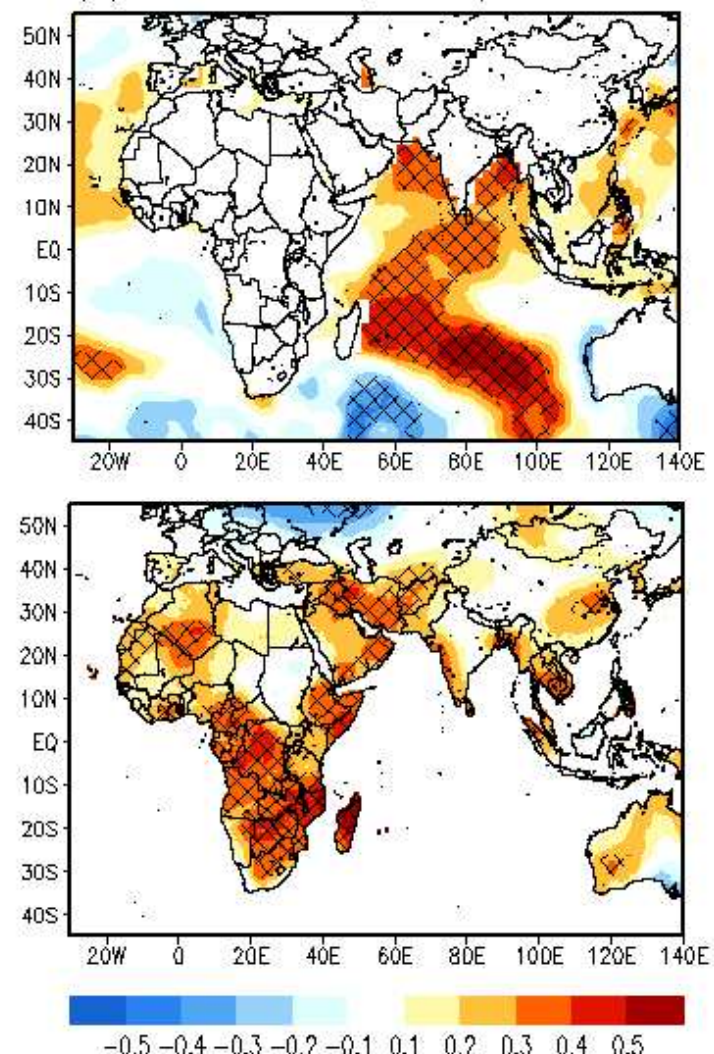

Fig. $6 \mathrm{EOF} 1$ (a) of the service-sectoral GDP in the target area $\left(30^{\circ} \mathrm{W}-125^{\circ} \mathrm{E}, 45^{\circ} \mathrm{S}-45^{\circ} \mathrm{N}\right)$ during the period 1970-2014. The percentage variance is $23.5 \%$ explained by the EOF1 spatial pattern. PC1 time series for Fig. 6 (a) is denoted by red (for Fig. 1 (a), the blank line). The correlation value between the two is 0.85 over $99 \%$ confidence level in (b). Correlation coefficients of SST in the upper (c) and global temperature in the lower (c) with respect to the service sectoral PC1 time series during the period 1970-2014. 


\section{References}

Anttila-Hughes J, Hsiang S (2013) Destruction, disinvestment, and death: Economic and human losses following environmental disaster. SSRN Working Paper 2220501. https://gspp.berkeley.edu/research/working-paper-series/destruction-disinvestmentand-death-economic-and-human-losses-following-env. Accessed 20 December 2020

Arent DJ, Tol RSJ, Faust E, Hella JP, Kumar S, Strzepek KM, Tóth FL, Yan D (2014) Key economic sectors and services. In: Field CB, Barros VR, Dokken DJ, Mach KJ, Mastrandrea MD, Bilir TE, Chatterjee M, Ebi KL, Estrada YO, Genova RC, Girma BG, Kissel ES, Levy AN, MacCracken S, Mastrandrea PR, White LL (eds.) Climate change 2014: Impacts, adaptation, and vulnerability. Part A: Global and sectoral aspects. Contribution of working group II to the fifth assessment report of the Intergovernmental Panel on Climate Change. Cambridge University Press, Cambridge, United Kingdom and New York, pp 659-708

Bader J, and Latif M (2003) The impact of decadal-scale Indian Ocean sea surface temperature anomalies on Sahelian rainfall and the North Atlantic Oscillation. Geophys Res Lett, 30(22):2169. https://doi.org/10.1029/2003GL018426

Brown C, Meeks R, Hunu K, Yu W (2011). Hydroclimatic risk to economic growth in subSaharan Africa. Clim. Change (106):621-647. https://doi.org/10.1007/s10584-0109956-9

Bryceson, DF (1996) Deagrarianization and rural employment in sub-Saharan Africa: A sectoral perspective. World Dev 24(1):97-111. https://doi.org/10.1016/0305750X(95)00119-W

Buera FJ, Kaboski JP (2012a) The rise of the service economy. Am Econ Rev 102(6):25402569. https://doi.org/10.1257/aer.102.6.2540

Buera FJ, Kaboski JP (2012b) Scale and the origins of structural change. J Econ Theory 147(2):684-712. https://doi.org/10.1016/j.jet.2010.11.007

Burke M, Craxton M, Kolstad CD, Onda C (2016) Some research challenges in the economics of climate change. Clim Chang Econ 7(2):1650002. https://doi.org/10.1142/S2010007816500020

Burke M, Davis WM, Diffenbaugh NS (2018) Large potential reduction in economic damages under UN mitigation targets. Nature 557(7706):549. https://doi.org/10.1038/s41586-018-0071-9

Burke M, Hsiang SM, Miguel E (2015) Global non-linear effect of temperature on economic production. Nature 527(7577):235. https://doi.org/10.1038/nature15725

Carleton TA, Hsiang SM (2016) Social and economic impacts of climate. Science, 353(6304):aad9837. https://doi.org/10.1126/science.aad9837

Chenery HB (1960) Patterns of industrial growth. Am Econ Rev 50(4):624-654. https://www.jstor.org/stable/1812463

Chenery HB, Syrquin M, Elkington H (1975) Patterns of development, 1950-1970. Oxford University Press, London

Clark C (1940) The conditions of economic growth. Macmillan, London

Das S (2015) Temperature increase, labor supply and cost of adaptation in developing economies: evidence on urban workers in informal sectors. Clim Chang Econ, 06(02):1550007. https://doi.org/10.1142/S2010007815500074

Davis CL, Vincent K (2017) Climate risk and vulnerability: A handbook for Southern Africa. Pretoria, South Africa, CSIR.

Dell M, Jones BF, Olken BA (2012) Temperature shocks and economic growth: Evidence from the last half century. Am Econ J Macroecon 4(3):66-95. https://doi.org/10.1257/mac.4.3.66 
Deschênes O, Greenstone M (2011) Climate change, mortality, and adaptation: Evidence from annual fluctuations in weather in the US. Am Econ J Appl Econ 3(4):152-185. https://doi.org/10.1257/app.3.4.152

Eichengreen B, Gupta P (2011) The two waves of service-sector growth. Oxf Econ Pap, 65(1):96-123. https://doi.org/10.1093/oep/gpr059

Fan QIN, Davlasheridze M (2019) Economic impacts of migration and brain drain after major catastrophe: The case of Hurricane Katrina. Clim Chang Econ 10(1):1-21. https://doi.org/10.1142/S2010007819500040

Fankhauser S, McDermott TK (2014) Understanding the adaptation deficit: Why are poor countries more vulnerable to climate events than rich countries? Glob Environ Change 27:9-18. https://doi.org/10.1016/j.gloenvcha.2014.04.014

Feenstra, RC, Inklaar R, Timmer MP (2015) The next generation of the Penn World Table. Am Econ Rev 105(10):3150-3182. https://doi.org/10.1257/aer.20130954,

Fisher, AG (1939) Production, primary, secondary and tertiary. Econ Rec 15(1):24-38.

https://doi.org/10.1111/j.1475-4932.1939.tb01015.x

Francois J, Hoekman B (2010) Services trade and policy. J Econ Lit 48(3):642-692. https:// 10.1257/jel.48.3.642

Frölicher TL, Laufkötter C (2018) Emerging risks from marine heat waves. Nat Commun 9(1):650. https://doi.org/10.1038/s41467-018-03163-6

Gervais A, Jensen JB (2019) The tradability of services: Geographic concentration and trade costs. J Int Econ 118:331-350. https://10.1016/j.jinteco.2019.03.003

Harris I, Jones PD, Osborn TJ, Lister DH (2014) Updated high-resolution grids of monthly climatic observations-the CRU TS3. 10 dataset. Int J Climatol 34(3): 623-642. https://doi.org/10.1002/joc.3711

Heal G, Park J (2015) Goldilocks economies? Temperature stress and the direct impacts of climate change. NBER Working Paper 21119. NBER, Cambridge.

Heino M, Puma MJ, Ward PJ, Gerten D, Heck V, Siebert S, Kummu M (2018). Two-thirds of global cropland area impacted by climate oscillations. Nat Commun 9(1):1257. https://doi.org/10.1038/s41467-017-02071-5

Hock H, Weil DN (2012) On the dynamics of the age structure, dependency, and consumption. J Popul Econ 25(3):1019-1043. https://doi.org/10.1007/S00148-0110372-X

Hsiang SM (2010) Temperatures and cyclones strongly associated with economic production in the Caribbean and Central America. Proc Natl Acad Sci 107(35):15367-15372. https://doi.org/10.1073/pnas.1009510107.

Hsiang SM, Meng KC, Cane MA (2011) Civil conflicts are associated with the global climate. Nature 476(7361):438. https://doi.org/10.1038/nature10311

Iizumi T, Luo JJ, Challinor AJ, Sakurai G, Yokozawa M, Sakuma H, Yamagata T (2014) Impacts of El Niño Southern Oscillation on the global yields of major crops. Nat Commun 5:3712. https://doi.org/10.1038/ncomms4712

Im ES, Pal JS, Eltahir EA (2017) Deadly heat waves projected in the densely populated agricultural regions of South Asia. Sci Adv 3(8):e1603322. https://doi.org/10.1126/sciadv.1603322

Intergovernmental Panel on Climate Change (IPCC) (2014) Climate change 2014: The fifth assessment report of the IPCC. IPCC, Geneva.

Zolliffe IT (2002). Principal component analysis. (2nd ed.) Springer, New York.

Jury MR (2002) Economic impacts of climate variability in South Africa and development of resource prediction models. J Appl Meteorol 41(1):46-55. https://www.jstor.org/stable/26184931 
Kim JS, Kug JS, Jeong SJ, Huntzinger DN, Michalak AM, Schwalm CR, Wei Y, Schaefer, K (2017) Reduced North American terrestrial primary productivity linked to anomalous Arctic warming. Nat Geosci 10(8):572-576. https://doi.org/10.1038/ngeo2986

Kutznets S (1957) Quantitative aspects of economic growth of nations: II. industrial distribution of national product and labor force. Econ Dev Cult Change 5(4):1-111. https://www.jstor.org/stable/1151943

Lazo JK, Lawson M, Larsen PH, Waldman DM (2011). US economic sensitivity to weather variability. Bull Am Meteorol Soc 92(6):709-720. https://doi.org/10.1175/2011bams2928.1

Letta M, Tol RSJ (2019) Weather, climate and total factor productivity. Environ Resour Econ 73(1):283-305. https://doi.org/10.1007/s10640-018-0262-8

Lobell DB, Schlenker W, Costa-Roberts J (2011) Climate trends and global crop production since 1980. Science 333(6042):616-620. https://10.1126/science.1204531

Malik AS, Smith SC (2012) Adaptation to climate change in low-income countries: Lessons from current research and needs from future research. Clim Chang Econ 3(2):1250005. https://doi.org/10.1142/S2010007812500054

Mendelsohn R (2012) The economics of adaptation to climate change in developing countries. Clim Chang Econ 3(2): 1250006. https://doi.org/10.1142/S2010007812500066

Newell RG, Prest BC, Sexton SE (2018) The GDP-temperature relationship. Resources for the Future (RFF) Working Paper 18-17. RFF, Washington, DC.

Odell SD, Bebbington A, Frey KE (2018) Mining and climate change: A review and framework for analysis. Extr Ind Soc 5(1):201-214. https://doi.org/10.1016/j.exis.2017.12.004

Ogawa N, Kondo M, Matsukura R (2005) Japan's transition from the demographic bonus to the demographic onus. Asian Popul Stud 1(2):207-226. https://doi.org/10.1080/17441730500317451

Pretis F, Schwarz M, Tang K, Haustein K, Allen MR (2018) Uncertain impacts on economic growth when stabilizing global temperatures at $1.5^{\circ} \mathrm{C}$ or $2^{\circ} \mathrm{C}$ warming. Phil Trans $\mathrm{R}$ Soc A 376(2119):20160460. https://doi.org/10.1098/rsta.2016.0460

Saji N, Goswami B, Vinayachandran P, Yamagata T (1999) A dipole mode in the tropical Indian Ocean. Nature 401(6751):360. https://doi: 10.1038/43854

Schlenker W, Lobell DB (2010) Robust negative impacts of climate change on African agriculture. Environ Res Lett 5(1):1-8. https://doi.org/10.1088/1748-9326/5/1/014010

Schlenker W, Roberts MJ (2009) Nonlinear temperature effects indicate severe damages to US crop yields under climate change. Proc Natl Acad Sci 106(37):15594-15598. https://doi.org/10.1073/pnas.0906865106

Sheehan J (2006) Understanding service sector innovation. Commun ACM 49(7):42-47. https://doi.org/10.1145/1139922.1139946

Sherwood SC, Huber M (2010) An adaptability limit to climate change due to heat stress. Proc Natl Acad Sci 107(21):9552-9555. https://doi.org/10.1073/pnas.0913352107

Smith TM, Reynolds RW, Peterson TC, Lawrimore J (2008) Improvements to NOAA's historical merged land-ocean surface temperature analysis (1880-2006). J Clim 21(10):2283-2296. https://doi.org/10.1175/2007jcli2100.1

Szirmai A, Verspagen B (2015) Manufacturing and economic growth in developing countries, 1950-2005. Struct Chang Econ Dyn 34:46-59. https://doi.org/10.1016/j.strueco.2015.06.002

Waha K, Krummenauer L, Adams S, Aich V, Baarsch F, Coumou D, Fader M, Hoff H, Jobbins G, Marcus, R, Mengel M, Otto IM, Perrette M, Rocha M, Robinson A, 
Schleussner CF (2017) Climate change impacts in the Middle East and Northern Africa (MENA) region and their implications for vulnerable population groups. Reg Environ Change 17(6):1623-1638. https://doi.org/10.1007/s10113-017-1144-2

Webster PJ, Moore AM, Loschnigg JP, Leben RR (1999) Coupled ocean-atmosphere dynamics in the Indian Ocean during 1997-98. Nature 401(6751):356. https://doi.org/10.1388/43848

Wirtz A, Löw P, Mahl T, Yildirim S (2013) Hitting the poor-public private partnerships as an option: impact of natural catastrophes in economies at various stages of development. Cambridge University Press, Cambridge

Yang J, Liu Q, Xie SP, Liu Z, Wu L (2007) Impact of the Indian Ocean SST basin mode on the Asian summer monsoon. Geophys Res Lett, 34(2). https://doi.org/10.1029/2006GL028571

Yusuf AA, Francisco H (2009) Climate change vulnerability mapping for Southeast Asia. Economy and Environment Program for Southeast Asia (EEPSEA), Singapore

Zivin JG, Neidell M (2014) Temperature and the allocation of time: Implications for climate change. J. Labor Econ 32(1):1-26. https://doi.org/10.1086/671766 

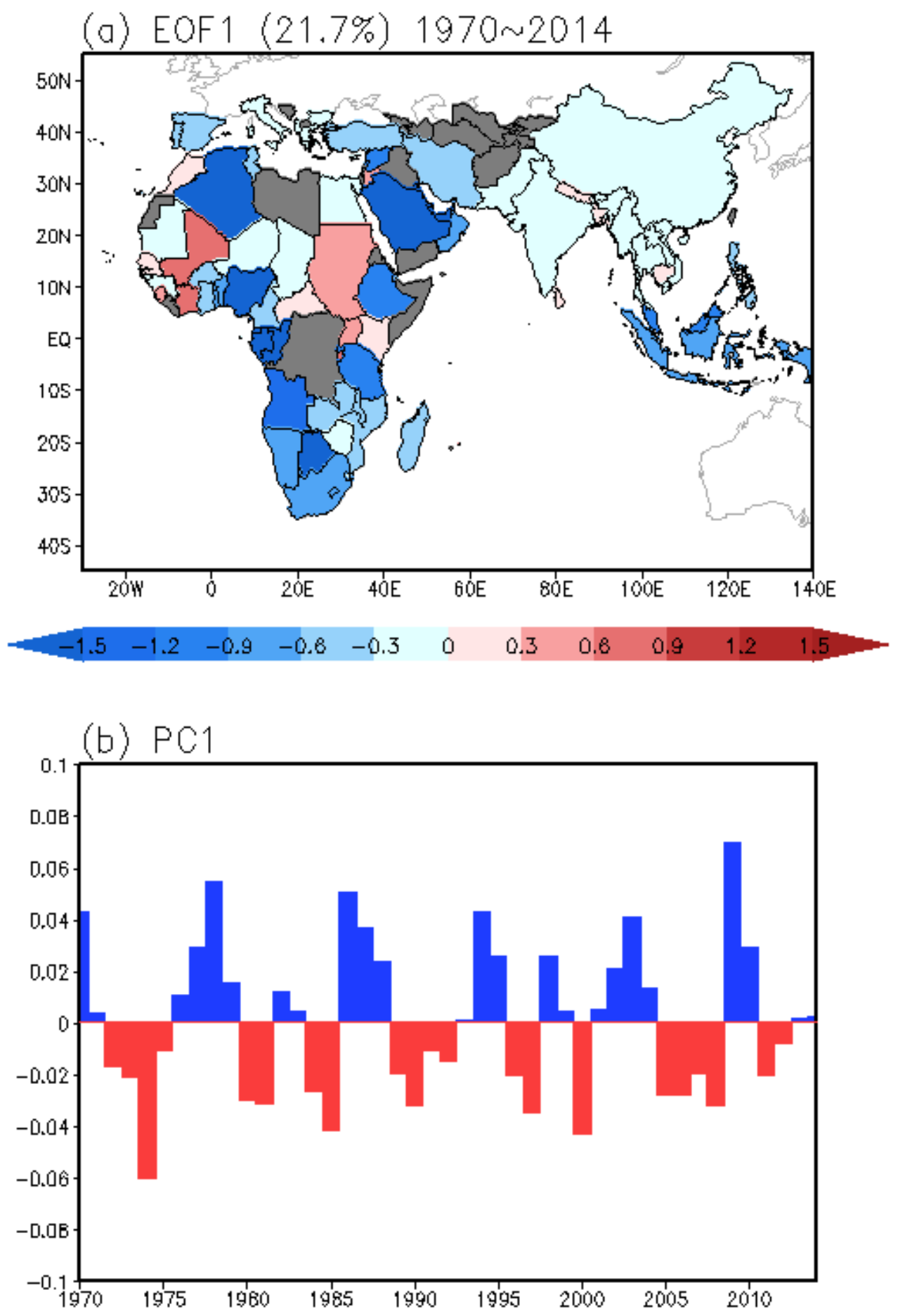

Figure 1

EOF1 (a) of GDP in the target area $\left(30^{\circ} \mathrm{W}-125^{\circ} \mathrm{E}, 45^{\circ} \mathrm{S}-45^{\circ} \mathrm{N}\right)$ during the period $1970-2014$. The percentage variance is $21.7 \%$ explained by the EOF1 spatial pattern. No data is denoted by gray shaded regions. The first principle component time series (b) is 10-year high pass filtered in the same period. 
Note: The designations employed and the presentation of the material on this map do not imply the expression of any opinion whatsoever on the part of Research Square concerning the legal status of any country, territory, city or area or of its authorities, or concerning the delimitation of its frontiers or boundaries. This map has been provided by the authors.

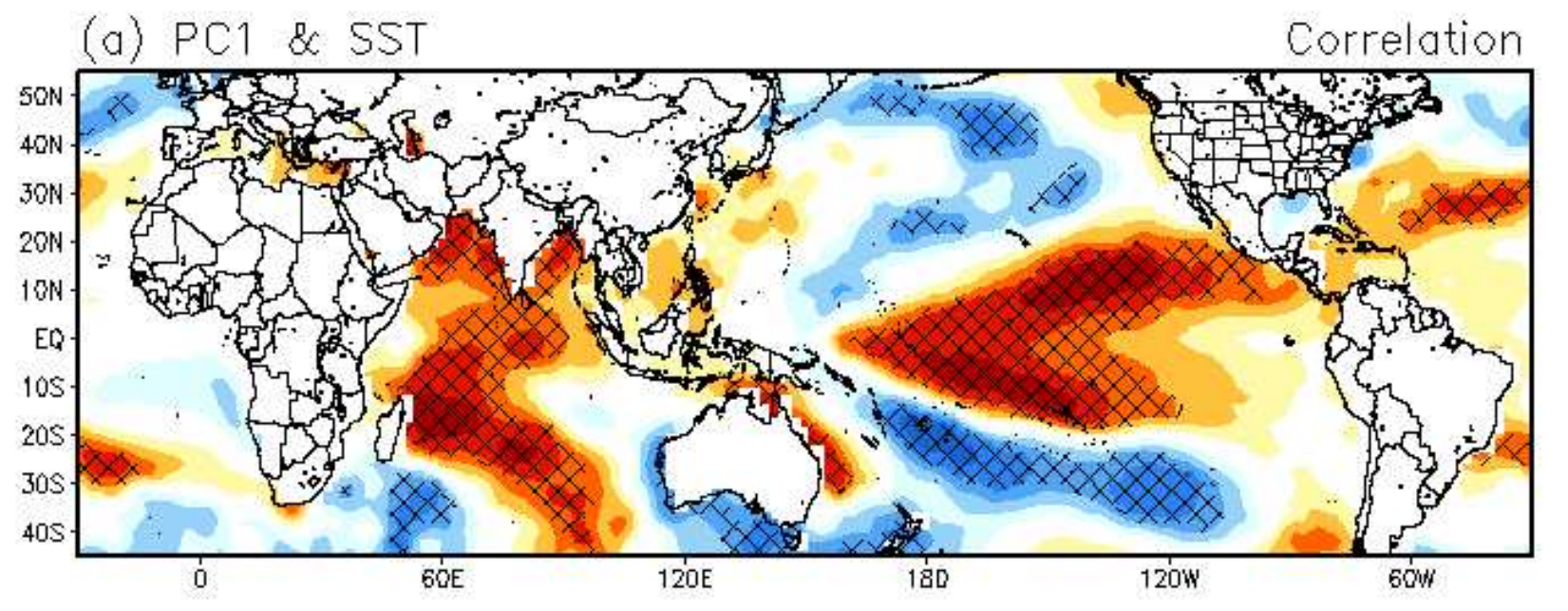

(b) PC1 \& Temperature

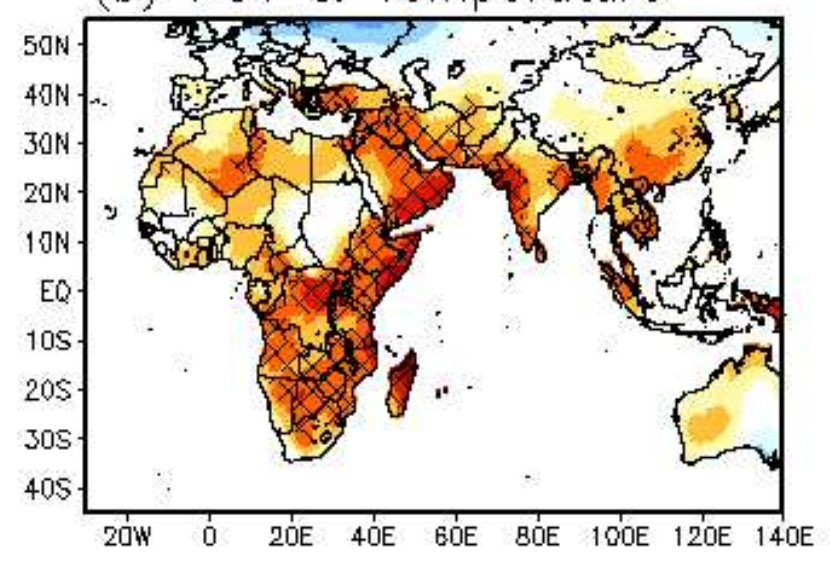

(c) PC1 \& Precipitation
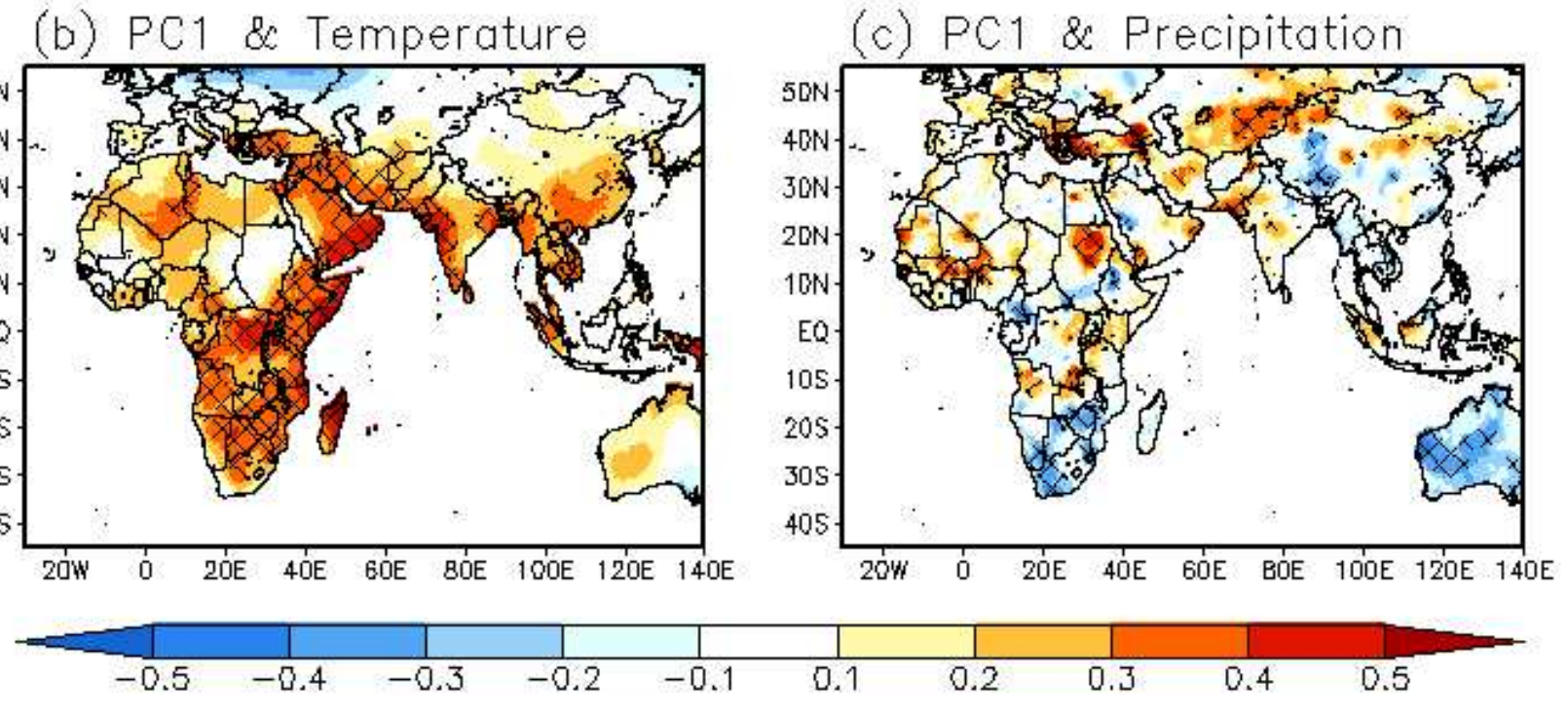

Figure 2

Correlation coefficients of SST (a), global temperature (b), and global precipitation (c) with respect to PC1 time series during the period 1970-2014. The values over 90\% confidence level based on the student t-test are denoted by hatch marks. Note: The designations employed and the presentation of the material on this map do not imply the expression of any opinion whatsoever on the part of Research Square concerning the legal status of any country, territory, city or area or of its authorities, or concerning the delimitation of its frontiers or boundaries. This map has been provided by the authors. 

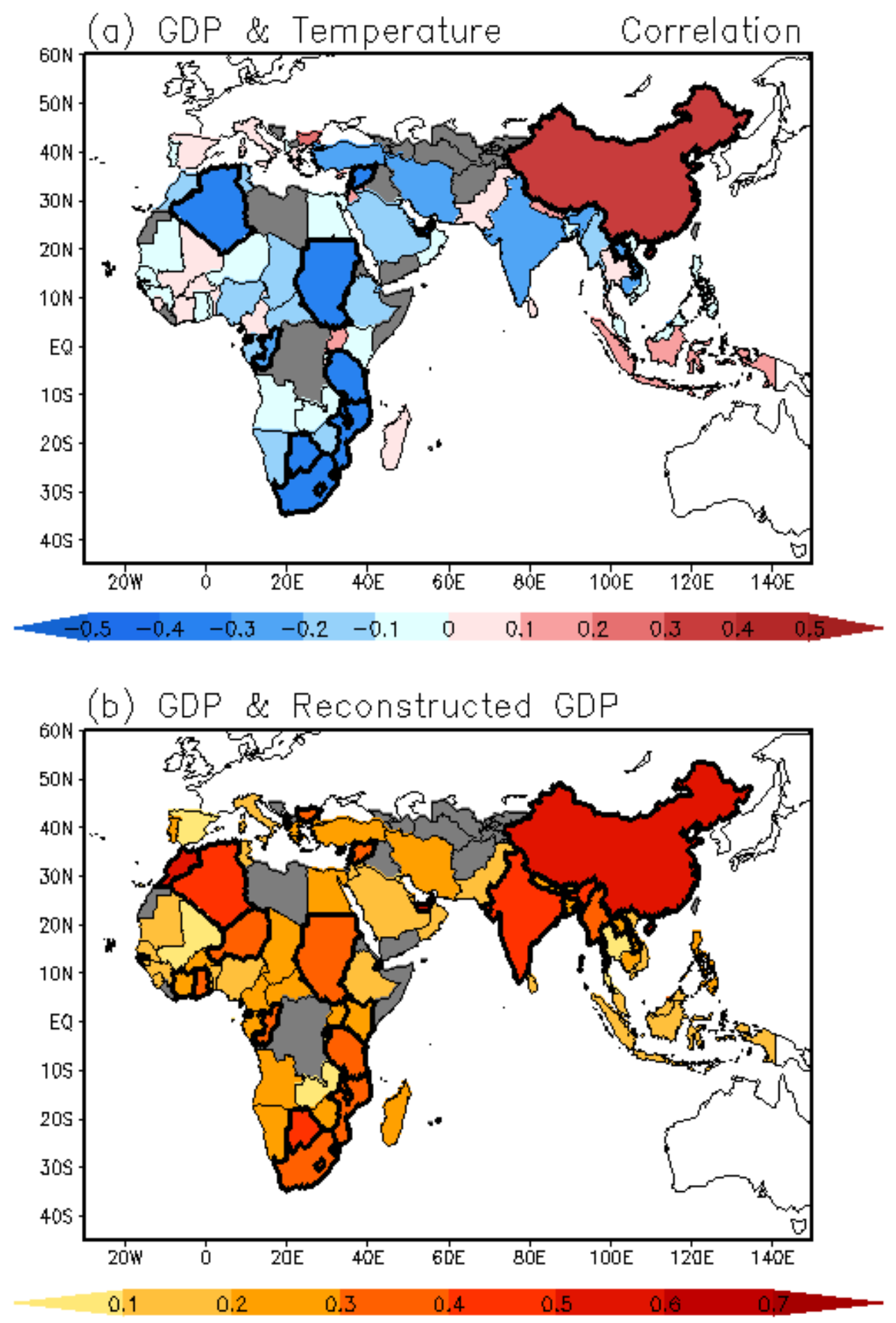

\section{Figure 3}

Correlation coefficients of local temperature with respect to GDP during the period 1970-2014 (a).

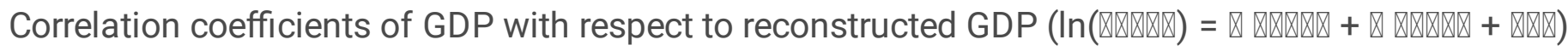
during the period 1970-2014 (b). The values over 90\% confidence level based on the student t-test are denoted by the thick black line. No data is denoted by gray shaded region Note: The designations employed and the presentation of the material on this map do not imply the expression of any opinion 
whatsoever on the part of Research Square concerning the legal status of any country, territory, city or area or of its authorities, or concerning the delimitation of its frontiers or boundaries. This map has been provided by the authors.
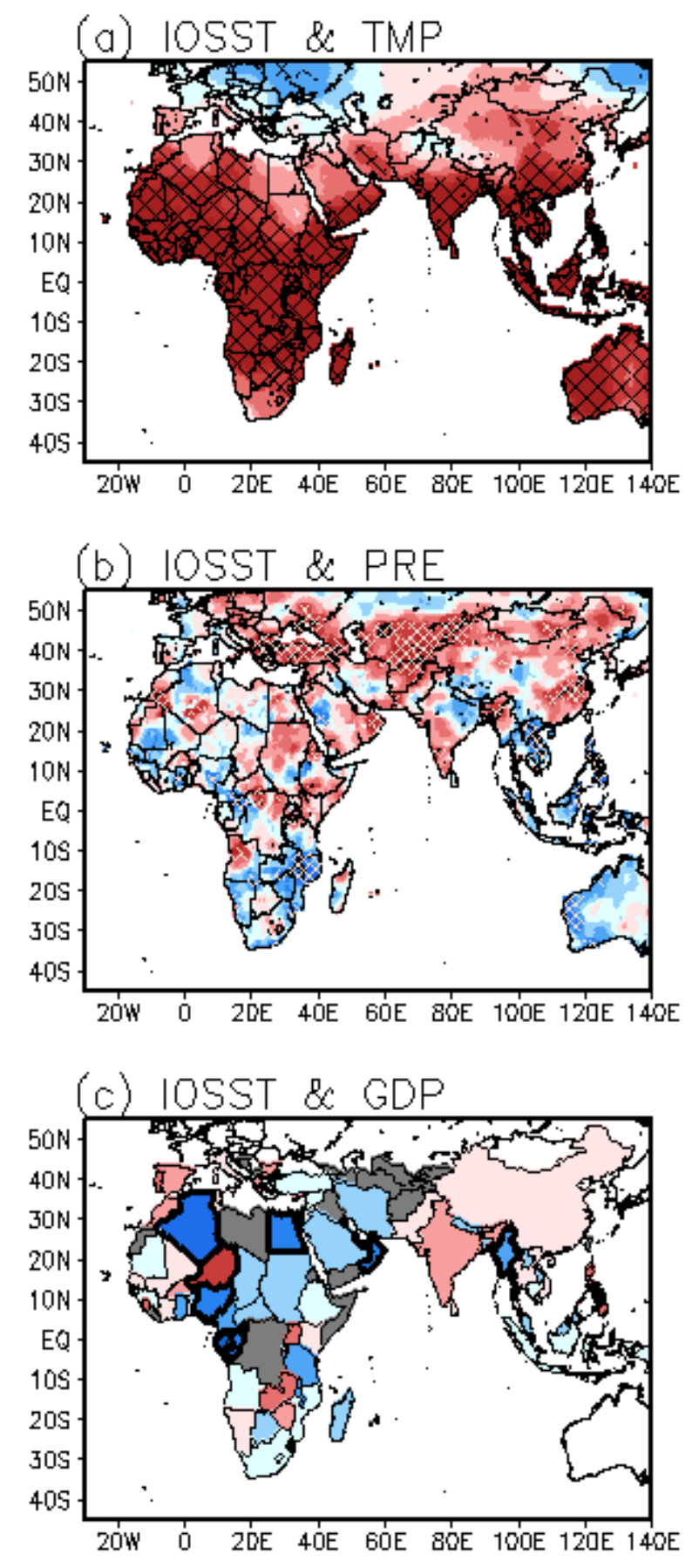

$\begin{array}{llllllll}-0.5-0.4-0.3-0.2-0.1 & \bullet & 0.1 & 0.2 & 0.3 & 0.4 & 0.5\end{array}$

Figure 4

Correlation coefficients of global temperature (a), global precipitation (b), and GDP (c) corresponding to the reconstructed index based on the Indian Ocean SST $\left(50^{\circ}-100^{\circ} \mathrm{E}, 20^{\circ} \mathrm{S}-30^{\circ} \mathrm{N}\right)$. The values over $90 \%$ 
confidence level based on the student t-test are denoted by hatch marks $(a, b)$ or thick black line (c) Note: The designations employed and the presentation of the material on this map do not imply the expression of any opinion whatsoever on the part of Research Square concerning the legal status of any country, territory, city or area or of its authorities, or concerning the delimitation of its frontiers or boundaries. This map has been provided by the authors.
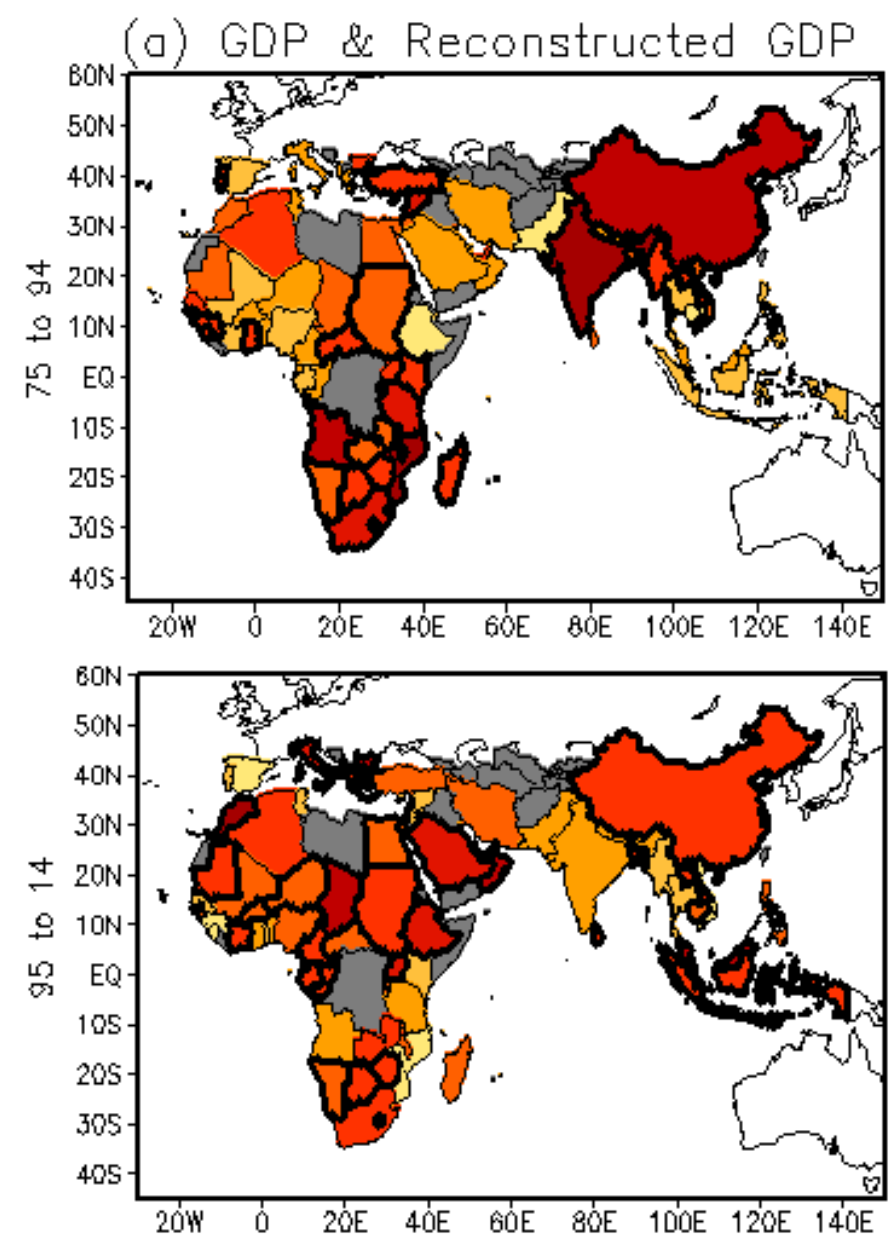

$\begin{array}{lllll}0.1 & 0.2 & 0.3 & 0.4 & 0.5\end{array}$

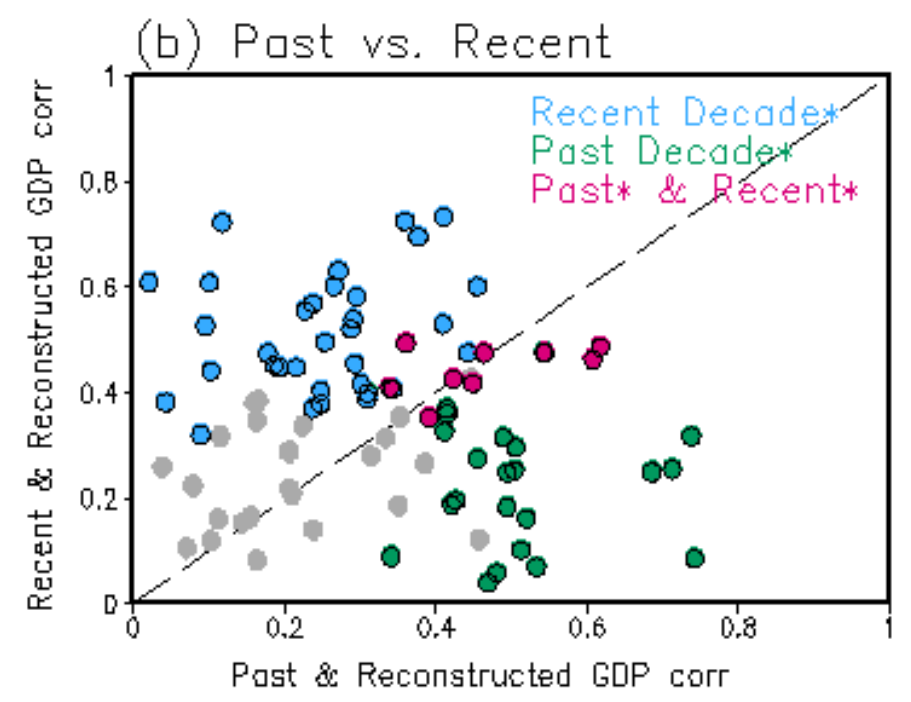

Figure 5

Correlation coefficients of GDP with respect to reconstructed GDP from 1975 to 1994 (the past decades) in the upper (a). Correlation coefficients of GDP with respect to reconstructed GDP from 1995 to 2014 (the recent decades) in the lower (a). Scatter diagrams for the correlations between GDP and reconstructed GDP for the past decades and the recent decades by country. The values over $90 \%$ confidence level of the past decades, recent decades, and both denoted by green, blue, and pink respectively. Note: The designations employed and the presentation of the material on this map do not imply the expression of any opinion whatsoever on the part of Research Square concerning the legal status of any country, 
territory, city or area or of its authorities, or concerning the delimitation of its frontiers or boundaries. This map has been provided by the authors.

(a) Service EOF1 (23.5\%)

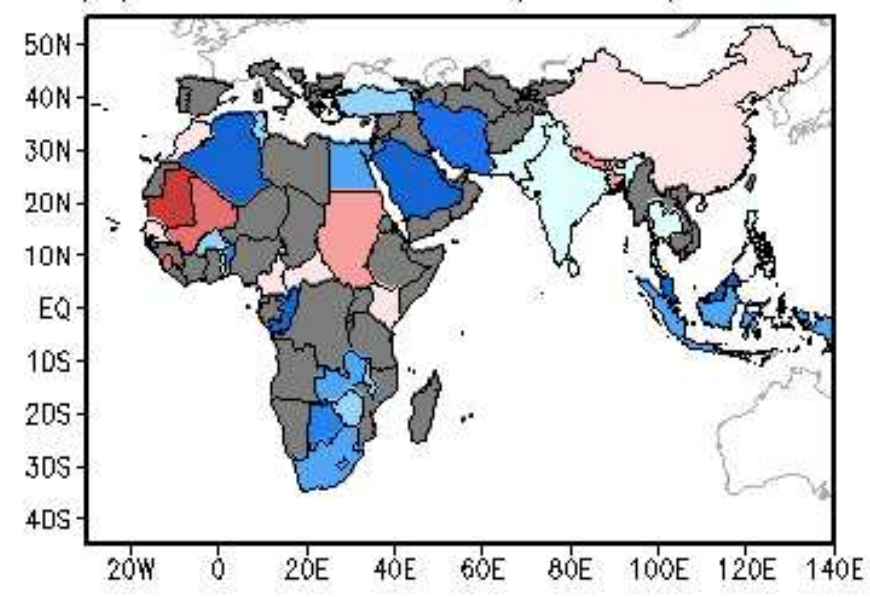

$\begin{array}{llllllll}-1.5-1.2-0.9-0.6-0.3 & 0 & 0.3 & 0.6 & 0.9 & 1.2 & 1.5\end{array}$

(b) Service PC1 (Corr 0.85***)

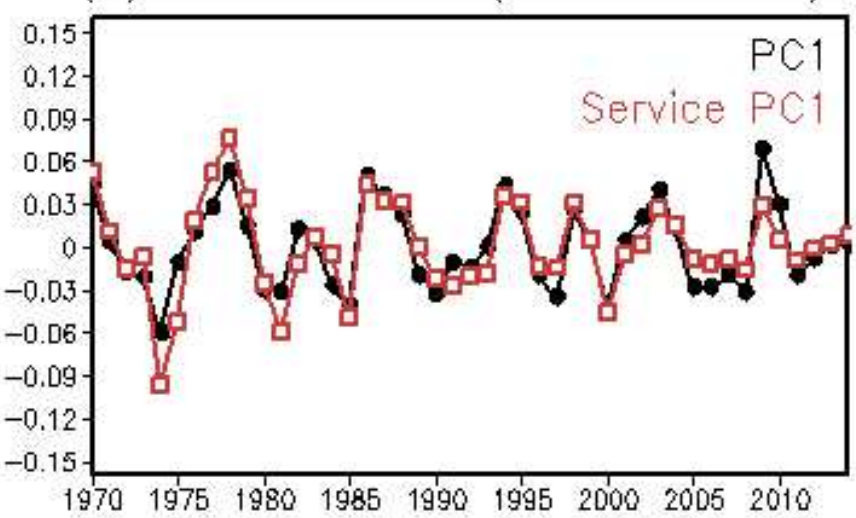

(c) PC1 \& SST, Temperature
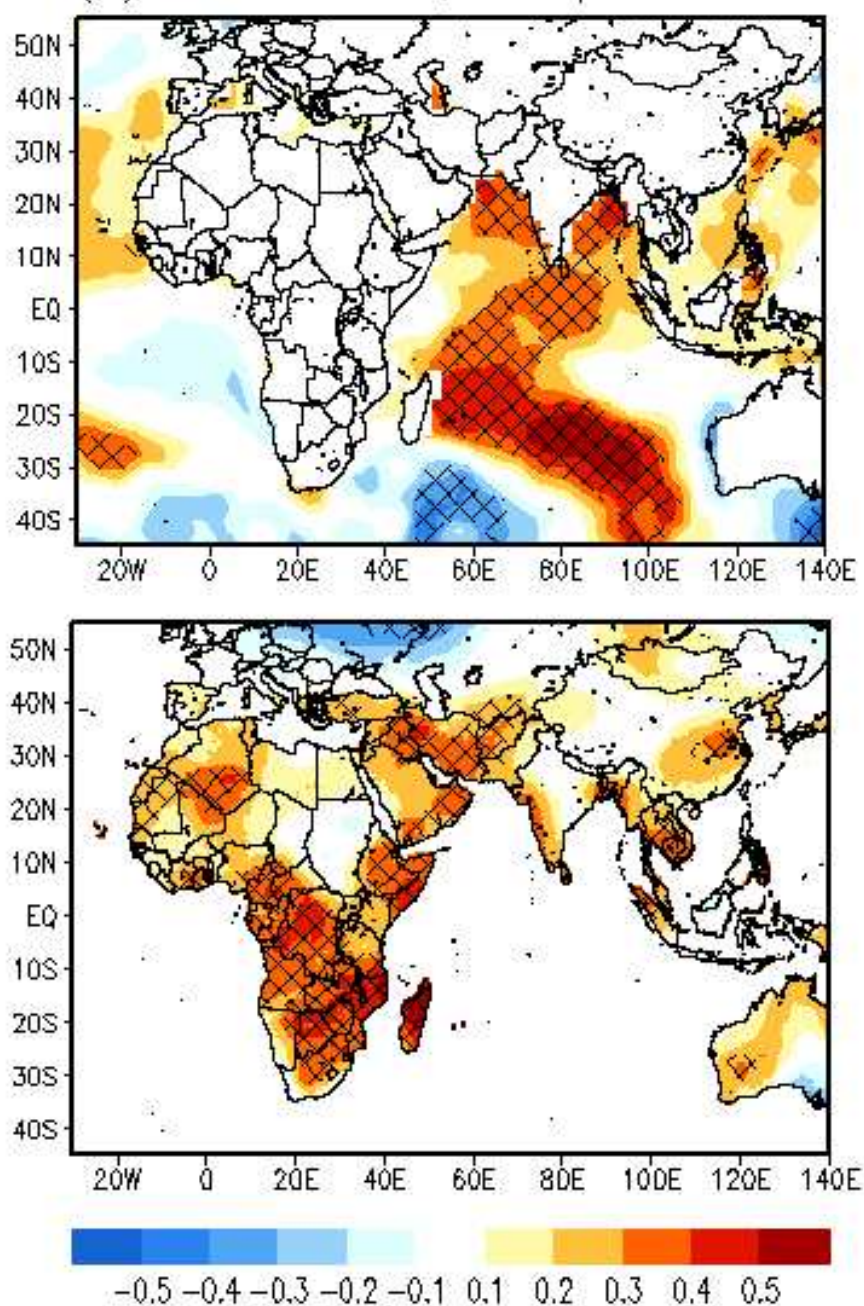

$-0.5-0.4-0.3-0.2-0.1 \quad 0.1 \quad 0.2 \quad 0.3 \quad 0.4 \quad 0.5$

Figure 6

EOF1 (a) of the service-sectoral GDP in the target area $\left(30^{\circ} \mathrm{W}-125^{\circ} \mathrm{E}, 45^{\circ} \mathrm{S}-45^{\circ} \mathrm{N}\right)$ during the period 1970-2014. The percentage variance is $23.5 \%$ explained by the EOF1 spatial pattern. PC1 time series for Fig. 6 (a) is denoted by red (for Fig. 1 (a), the blank line). The correlation value between the two is 0.85 over $99 \%$ confidence level in (b). Correlation coefficients of SST in the upper (c) and global temperature in the lower (c) with respect to the service sectoral PC1 time series during the period 1970-2014. Note: The designations employed and the presentation of the material on this map do not imply the expression of any opinion whatsoever on the part of Research Square concerning the legal status of any country, territory, city or area or of its authorities, or concerning the delimitation of its frontiers or boundaries. This map has been provided by the authors. 